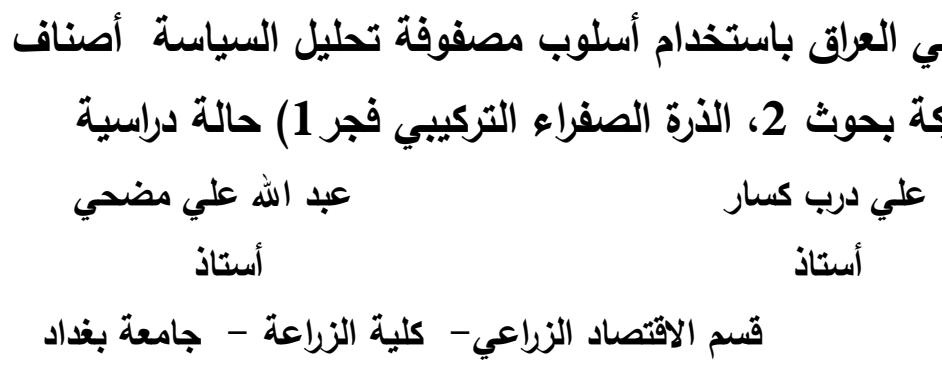

قسم الاقتصاد الزراعي- كلية الزراعة - جامعة بغداد

\section{وزارة الزراعة-الثركة العامة للتجهيزات الزراعية \\ Mohjoker1986@yahoo.com}

يهاف البحث إلى دراسة أولويات الاستثمار في البحث العلمي الزراعي في العرلق لثثلاثة أصناف من محاصيل الحبوب المستتبطة هي (رذ عنبر البركة بحوث2 ، الذرة

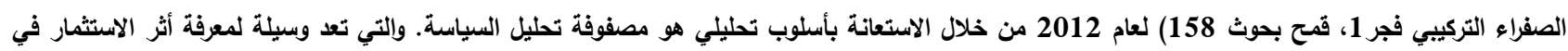

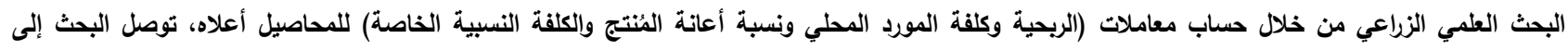

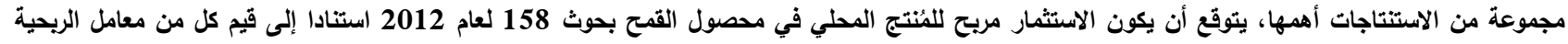

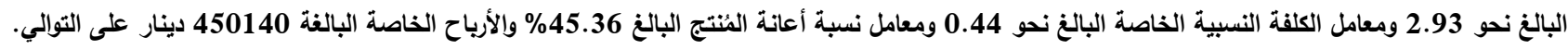

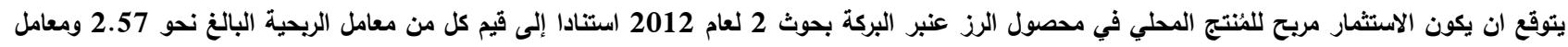

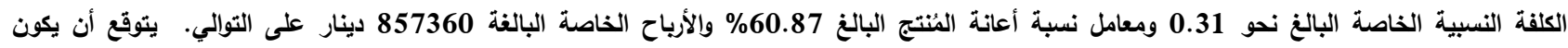

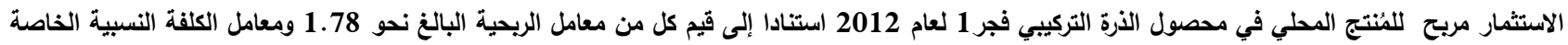

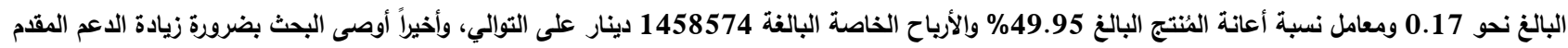

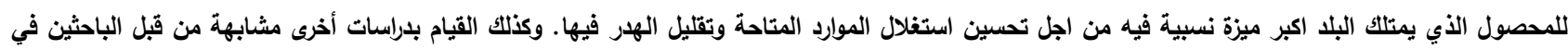

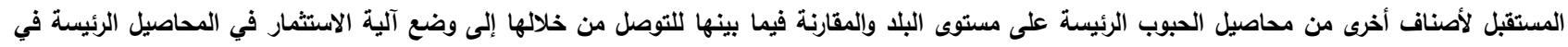
العراق التي تفيد الباحث والمُنتج المحلي والمستثمر الزراعي في توجيه استثماراته. الكلمات المفتاحية: الاستثمار، البحث العلمي، مصفوفة تحليل السياسة. "البحث مستل من أطروحة دكتوراه للباحث الأول.

The Iraqi Journal of Agricultural Sciences -797-811: (3) 48/ 2017

Lateef \& et al.

\title{
INVESTMENT PRIORITIES IN THE AGRICULTURAL SCIENTIFIC RESEARCH IN IRAQ USING POLICY ANALYSIS MATRIX APPROACH CEREALS CROPS (RICE AMBER AL BARAKA BUHOOTH2, CORN SYNTHETIIC GENOTYPE FAJER 1, AND WHEAT BUHOOTH 158) STUDY CASE
}

\section{M .A . Lateef* \\ Researcher}

Ministry of Agriculture, State for the Agricultural Supplies

Mohjoker1986@yahoo.com

\section{ABSTRACT}

The aim of this study is to focus on the investment priorities in the agricultural scientific research in Iraq for three cereals crops (Rice Amber Al Baraka Buhooth2, Corn Synthetic genotype Fajer1, and wheat Buhooth158) for the year (2012) respectively by using analysis method named police Analysis Matrix. This method is considered being a way of knowing the impact of investment in the agricultural scientific research, and it is done by calculating Profitability coefficient, Domestic Resource Cost coefficient, Producer Subsidy Ratio coefficient, and Private Cost coefficient Ratio for the cereals crops mentioned above. The research found a set of results, the most important result showed that .The investment was profitable for domestic producer for the wheat Buhooth158 for the year 2012 based on the values of profitability coefficient which was about 2.93 and private cost coefficient ratio which was about 0.44 , producer subsidy ratio coefficient which was $45.36 \%$ and private profits which were 450140 respectively. The investment was profitable for domestic producer for the variety Amber Al Baraka Buhooth2 for the year 2012 based on the values of profitability coefficient which was about 2.57, private cost coefficient ratio which was about 0.31 , producer subsidy ratio coefficient which was $60.87 \%$ and private profits which were 857360 respectively. The investment was profitable for domestic producer for the variety Synthetic genotype Fajer1 for the year 2012 based on the values of profitability coefficient which was about 1.78 and private cost coefficient ratio which was about 0.17 and producer subsidy ratio coefficient which was $49.95 \%$ and private profits which were 1458574 respectively Finally, it is highly recommended that support should be increased for variety that the country has greater comparative advantage in order to improve the utilization of available resources and reduce wasted resources. Moreover, similar studies should be done in the future by other researchers for the major cereal crops at the country level in order to do comparison between them to set an investment mechanism which help both the researcher, local producer and agricultural investor in directing its resources.

Key words: Investment, scientific research, Policy analysis matrix.

*Part of Ph.D. Dissertation for the first author. 
الاستثمار وانطلق البحث من فرضية مفادها بأنه بالاعتماد

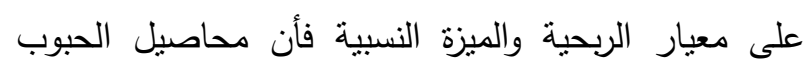

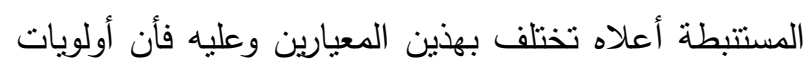

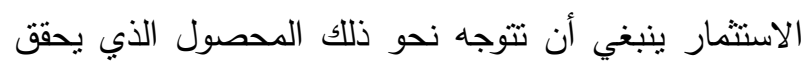

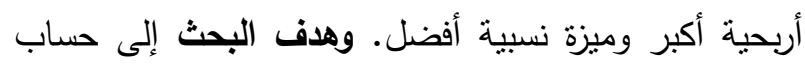
مصفوفة تحليل السياسة لمحاصيل الحبوب المستتبطة (قمح بحوث 158، رز عنبر البركة بحوث2، الذرة الصفراء التركيبي فجر 1) من قبل دائرة البحوث الزراعية ، تحديد

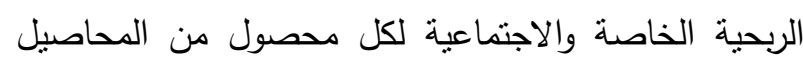
المذكورة أعلاه. فضلا عن تقدير الميزة النسبية لها وصولا

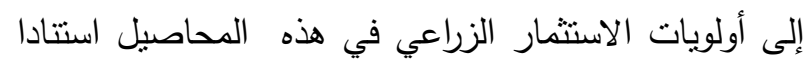
إلى المعايير أعلاه. المواد والطرائق قسم البحث إلى أولا: بيان نتائج حساب مصفوفة تحليل السياسة لمحصول القمح بحوث 158 لعام 2012 ثنانيا: نتائج حساب مصفوفة تحليل السياسة لمحصول الرز عنبر البركة بحوث2 للعام نفسه. ثالثاً: بيان نتائج حساب مصفوفة لثابلة تحليل السياسة لمحصول الذرة الصفراء التركيبي فجر 1 لعام

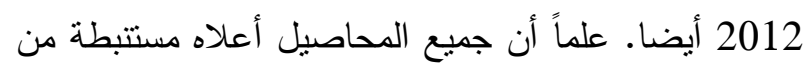
قبل دائرة البحوث الزراعية. مصفوفة تحليل السياسة هي عبارة عن أسلوب تحليلي رياضي وهذا النظام يستعمل نهلئل

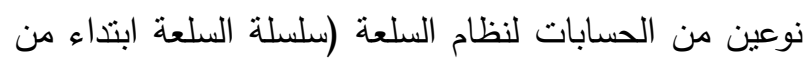

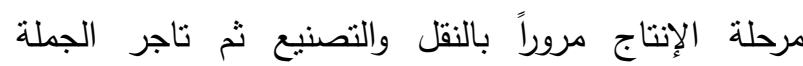

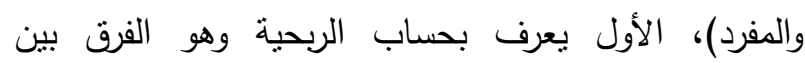

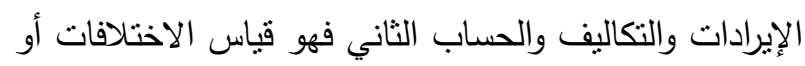
قياس تأثثرات السياسات المشوهة وفثنل السوق وهي توضح وتعطي مؤشرات حول ندخلات السياسات الحكومية وفثنل

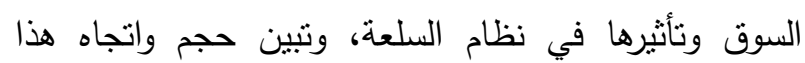

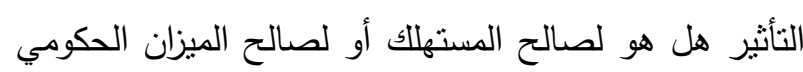
(7). وهي الأمور التي يفتقر إليها أسلوب التحليل التقليدي

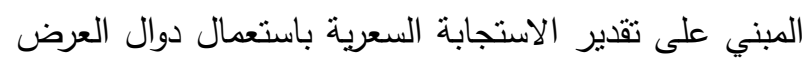
التي تعطي مؤشرات عامة ولا توضح اتجاه وتأثير سياسات التذخل الحكومي وفنثل السوق، وقد صممت مصفوفة تحليل السياسة على أساس معادلة الربح الآتية (16).

\section{المقدمة}

إن الاستثمارات العامة تتحدد من خلال المبالغ التي ترصدها

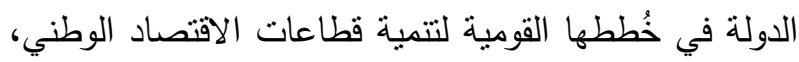
ويُطلق على صرف هذه المبالغ (بالإنفاق الاستثماري العام) إذ يضم الإنفاق الاستثماري العام أوجه عديدة منتوعة للإنفاق

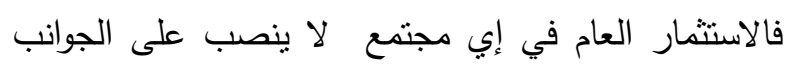

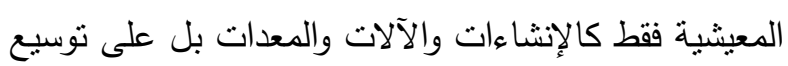
المعارف وقدرات العاملين في هذا المجتمع أي الاستثمار في الإنسان ذاته (3) وهذا يتحقق من خلال الإنفاق على التعليم والتدريب والصحة والبحوث العلمية والتقنية والتي يطلق عليها الاستثمارات الرائدة (10). ويهذف البحث والبه العلمي عاماً والزراعي منه بصوره خاصة إلى الوقوف على الحقائق وكثفها وتطوير ألآليات التي تخدم في محصلتها النهائية نمو

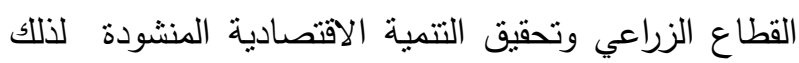
يمثل البحث العلمي الزراعي المستقبل المشرق للبلدان

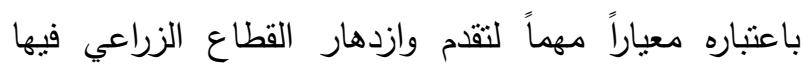

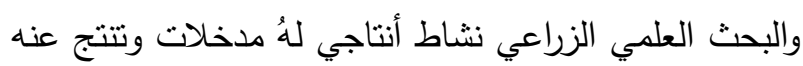
مخرجات وهذه المدخلات تتمثل بالموارد البشرية والمالية والفنية. أما مخرجات هذا النشاط فتتمثل بالدرجة الأساس

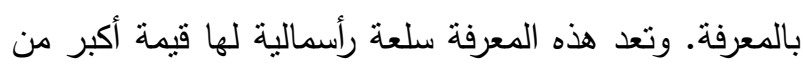
الإثكال الأخرى من السلع الرأسمالية المتمنلة بالبنايات والمكائن لكونها مربحة لمدة طويلة من الزمن وهذه المعرفة

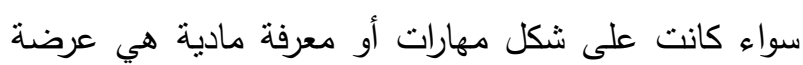
أيضاً للاندثار وبالتالي هي بحاجة مستمرة للإدامة والصيانة

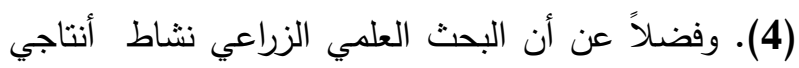
فهو نشاط استثماري أيضاً وهذا النشاط يكون عادة مكلفاً ويستغرق وقتاً قد يطول أو يقصر تبعاً لنوع البحث ودرجته (كأن يكون أساسي أو تطبيقي) قبل الحصول على العائد المترتب عليه. تبرز أهمية البحث من أهمية محاصيل الحبوب وكذلك أهمية الاستثمار في البحث العلمي الزراعي. بينما تمنلت مشكلته بكون يواجه القطاع الزراعي معوقات

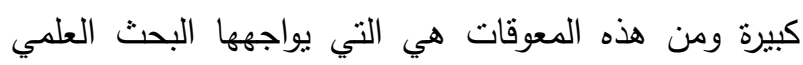
الزراعي وسُبل تطبيقه ليكون أداة أساسية في معرفة أي محصول من محاصيل الحبوب المستتبطة (قمح بحوث 158، رز عنبر البركة بحوث2، الذرة الصفراء التركيبي

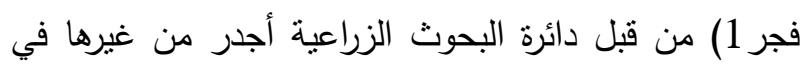


صافي التحويلات L نمثل تأثثرات سياسة التذخل G الحكومية وفنشل السوق على نظام السلعة.

.(14) $\mathrm{L}=\mathrm{D}-\mathrm{H}$ OR I-J - K

الربحية الخاصة: الربحية الخاصة D هي عبارة عن الفرق بين المجموع الكلي للإيرادات A أو (لكل وحدة مباعة) وبين تكاليف الإنتاج التي نشمل مجموع نكاليف المُدخلات المتاجر بها B والموارد المحلية C للوحدة من الناتج ويمكن الحصول

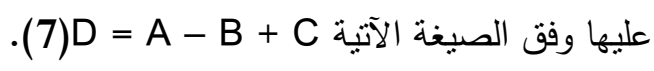

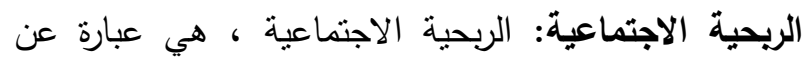

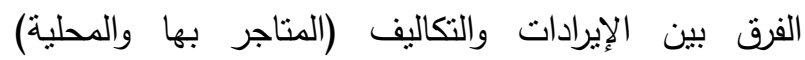
والمقيمة بالأسعار الاجتماعية ويمكن الحصول عليها وفق ولإنقالئ

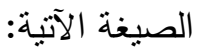

.(16) $H=E-F+G$ OR $\quad H=E-F-G$

استعمال مصفوفة تحليل السياسة: يمكن استعمال مصفوفة

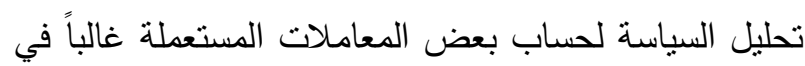
قياس اثر سياسة ما على الأسعار وعلى كفاءة استخدام المورد (7). وأهم هذه المعاملات مبينة بالجدول 2. جدول 2. بعض المعاملات التي تمكنتا من قياس أثر السياسة التلخلية في كفاعة استخدام الموارد.

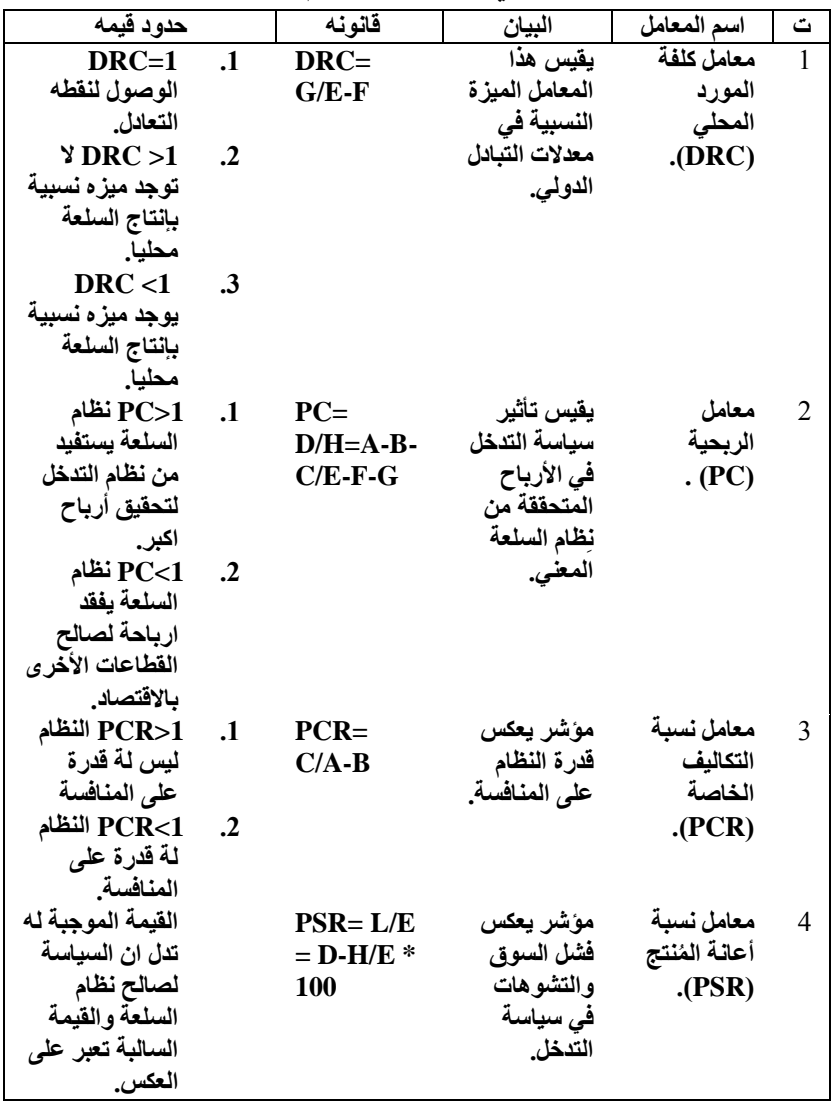

source: Monk, Erice, A. and Scott, r., Pearson, (1989), P.30
Profit $=$ Revenue - cost. $=$ e $(P$ q) $Q-$ e (P t) It - (Pn) In $-\mathbf{x}$.

سعر الصرف التوازني للعملة المحلية. e Pq . سعر المدخلات المتاجر بهات Pt - سعر الموارد المحلية غير المتاجر بها Pn = It = In تكاليف تأثير بعض العوامل الخارجية غير المباشرة. X مثل نقص المعلومات،مخاطرة،احتكار . = Sمية الناتج الهيكل التظظيمي وتحويلات المصفوفة يتكون هيكل المصفوفة من ثناثة صفوف وأربعة أعمدة وكما

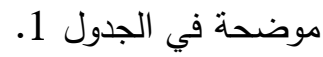
جدول 1. هيكل مصفوفة تحليل السياسة

\begin{tabular}{|r|c|c|c|c|}
\hline & Revenue & \multicolumn{2}{|c|}{ Costs } & Profits \\
\cline { 3 - 4 } & & $\begin{array}{c}\text { Tradable } \\
\text { inputs }\end{array}$ & $\begin{array}{c}\text { Domestic } \\
\text { resources }\end{array}$ & \\
\hline $\begin{array}{r}\text { Private } \\
\text { price }\end{array}$ & A & B & C & D \\
$\begin{array}{r}\text { Social } \\
\text { price }\end{array}$ & E & F & G & H \\
\cline { 1 - 1 } Transfers & I & J & K & L \\
\hline
\end{tabular}

source: Monk, Erice, A. and Scott, r., Pearson, (1989), P.15

يمثل الصف الأول للمصفوفة أسعار السوق الخاصة A الأسعار المحلية) لنظام السلعة لكل من العائد الإجمالي والمدخلات المتاجر بها B وكلفة الموارد المحلية C والأرباح الخاصة D. أما الصف الثاني فيمثل الأسعار الأجنماعية (أسعار الظل) لكل من العائد الإجمال E وكلفة المدخلات المتاجر بها F وكلفة الموارد المحلية G والأرباح الأجتماعية ولائ

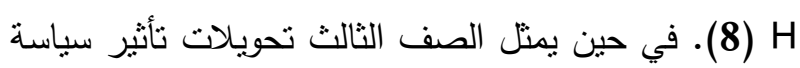
التشخل وفنثل السوق ويشتنمل على تحويلات الناتج ا وهو الفرق بين سعر السوق المحلي والسعر الأجتماعي للناتج تحويلات كلفة المدخلات المتاجر بها ل وهي عبارة A - E عن الفرق بين كلفة المدخلات المتاجر بها بسعر السوق

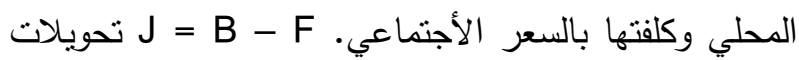
الموارد المحلية K وهي عبارة عن الفرق بين أسعار الموارد

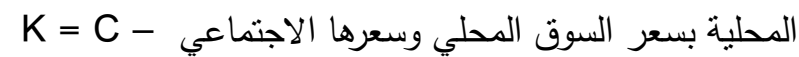


حساب الصف الأول من المصفوفة بالأسعار الخاصة (الفعلية ) لعام 2012 لمحصول القمح بحوث 158

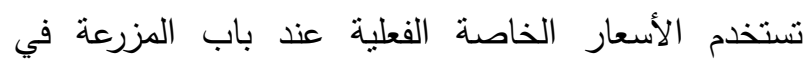

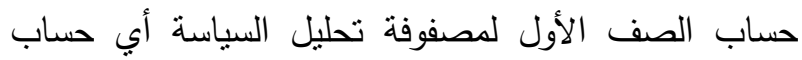
كلفة عناصر الإنتاج والعائد والربحية بصورة مفصلة. أما كلفة

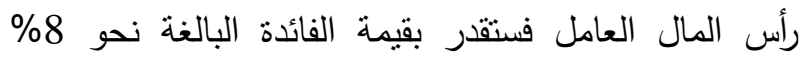
(6). بلغت إنتاجية الدونم الواحد 1350 كغم لمحصول القمح بحوث 158 في المنطقة المروية (1). كما بلغ سعر الثراء من قبل الدولة بنحو 686 دينار/ كغم للعام نفسه (11). تمت إضافة قيمة المخلفات الثانوية (التبن) والبالغة نحو لحم 20000 دينار / دونم إلى الإيراد (9). جدول 5. ميزانية الحقل لتكاليف عناصر الإنتاج والعائد والريحية الخاصة بالأسعار الخاصة لمحصول القمح بحوث لـول 158

\begin{tabular}{|c|c|c|c|}
\hline كلفئة عناصر الإجنم & سينار/كفم الوحدة الواحدة & عناصر الإتتاج & المدخلات \\
\hline 24010 & 686 & الألسمدة & المدخلات المتاجر \\
\hline 35000 & 500 & 1 - سماد يوريا & بها \\
\hline 19200 & 480 & 2 - سماد مركب & \\
\hline 30000 & 30000 & مبيدات أدغال & Tradable \\
\hline 26250 & 750 & وقود محركات السقي & $\begin{array}{l}\text { Inputs } \\
\text { (B) }\end{array}$ \\
\hline 134460 & & & المجموع \\
\hline 20000 & 40000 & 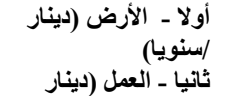 & غير المتاجر بها المحاية \\
\hline 15000 & & /سناعة) ويشمل & (C) \\
\hline 100000 & 2500 & 1 - تحضير الأرض & \\
\hline 25000 & 2500 & 2 - السقي & Non Tradable \\
\hline 25000 & 2500 & 3 - العنايةً بالمحصول & Inputs \\
\hline 12500 & 2500 & 4- الحصاد اليذوي & \\
\hline 4000 & $\begin{array}{c}\mathbf{2 5 0 0} \\
\mathbf{5 0 0 0 0}\end{array}$ & 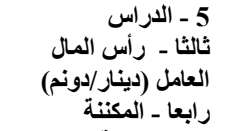 & \\
\hline 60000 & & (دينار/ساعة) وتثمل & \\
\hline 100000 & $\begin{array}{l}15000 \\
50000\end{array}$ & 2 - الحصنير الميكانيك & \\
\hline 361500 & 49596 (التكاليف) & $=361500+134460$ & المجموع \\
\hline 946100 & $926100+20000$ & 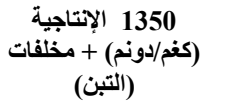 & العاند (A) \\
\hline & $450140=495960-$ & 6100 & $\begin{array}{c}\text { الربحية الخاصة } \\
\text { (D) }\end{array}$ \\
\hline
\end{tabular}

حساب الصف الثاني لمصفوفة تحليل السياسة بالأسعار الاجتماعية لإنتاج محصول القمح بحوث 158 بلغ السعر بالهرئ

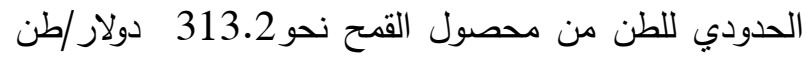
(12). وبإضافة كلفة النقل والتامين إلى الحدود والبالغة نحو 40 دولار/طن (5).سوف نحصل على السعر الاستنيرادي

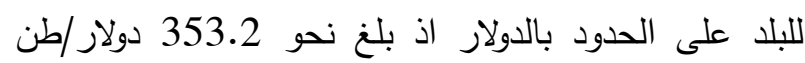

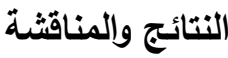

أولا:- نتائج حساب مصفوفة تحليل السياسة لمحصول قمح الخبز بحوث 158 لعام 2012: استتبط هذا المحصول عام 2012 من قبل دائرة البحوث الزراعية / قعم بحوث محاصيل الحبوب والبقوليات بأشراف فريق عمل مكون من

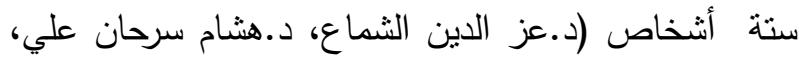
جمال عبد محمد، كفاح توفيق صالح، مهنا جارو، محمد عمر) واهم مواصفاته هي (متفوق في الإنتاج، مقاوم للاضطجاع مقاوم للانفراط مقاوم للإمراض وخاصة الصنا

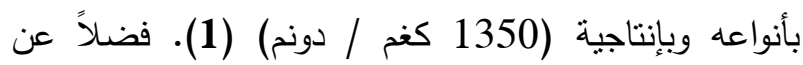
مواصفاته النوعية الموضحة بالجدول 3. أما الجدول 4.

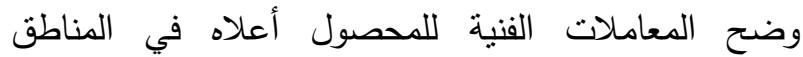
المروية.

جدول 3. مكونات الحاصل والمواصفات النوعية لقمح الخبز

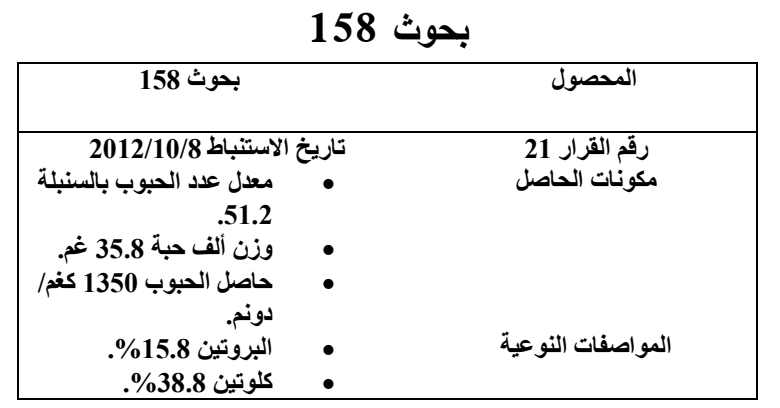

المصدر: من إعداد الباحث استنادا إلى نشرات مختلفة

جدول 4. المعاملات الفنية ( Technical coefficients)

لمحصول القمح بحوث 158 في المنطقة المروية

\begin{tabular}{|c|c|c|}
\hline الكمية لدونم الواحد & عناصر الإنتاج & المدخلات \\
\hline \multirow[t]{2}{*}{35 كفم / دونم } & البذور & \\
\hline & الأسمدة & المدخلات المتاجر بها \\
\hline 70 كغم / دونم على & 1 - سماد يوريا & \\
\hline دفعتين & & Tradable Inputs \\
\hline 40 & 2 - سماد مركب & \\
\hline 1 & مبيدات أدغال & \\
\hline 35 & وقود محركات السقي & \\
\hline \multirow[t]{2}{*}{ 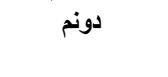 } & أولا - الأرض & \\
\hline & ثانيا ــ العمل ويشمل & الموارد المحلية غير \\
\hline ساعة / دونم & 1 ـ تحضير الأرض & المتاجر بها \\
\hline 40 س $\quad$ ساعة / دونم & 2 - السقي & \\
\hline 10 ساعة / دونم & 3 - العناية بالمحصول & Non Tradable \\
\hline $10 \quad 10$ & 4 - الحصاد اليدوي & Inputs \\
\hline 5 & 5 - الدراس & \\
\hline \multirow[t]{2}{*}{50 ألف دينار للاونم } & ثالثا ـــرأس المال العامل & \\
\hline & رابعا ـ المكتنة وتثمل & \\
\hline ساعة / دونم & 1 ـ تحضير الأرض & \\
\hline \multirow[t]{2}{*}{ ساعة / دونم } & 2 - الحصاد الميكانيك & \\
\hline & الإنتاجية 1350 كفم/دونم & \\
\hline
\end{tabular}

المصدر :المدخلات المتاجر بها اعتمادا على نشرات مختلفة ، الموارد المحلية ،وجدان ، 2011،ص87، الإنتاجية دائرة البحوث الزراعية 
المركب ولهذا فان السعر الظلي للكيلوغرام تساوي 678.3 دينار/كغ ولسماد اليوريا تكون القيمة المساواتية للاستيراد عند باب المزرعة للطن الواحد هي 608550.9 دينار/طن

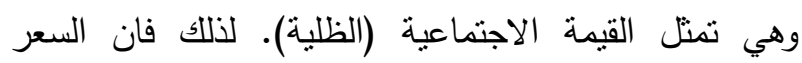

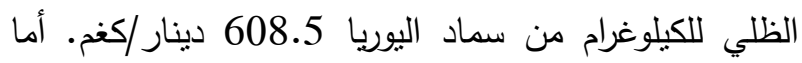
المبيدات فان الأسعار الاستيرادية لمبيد 2,D,Dهي 3.8 دولار/لتز ويضمنها تكاليف النقل إلى المخازن الرئيسية

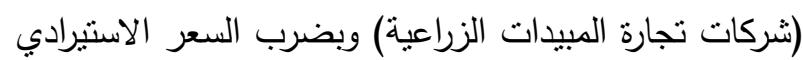
للمبيد بسعر الصرف التوازني 1233 (18) نحصل على القيمة الاجتماعية (الظلية) للمبيد 1233 X 1285.4 = دينار/لتز أي إن كلفة المبيد الظلية. 1 X 1 X

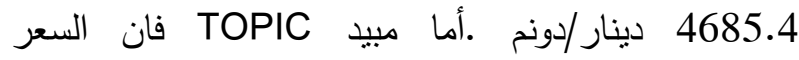
الاستيرادي هو 18.7 دولار/لتز ويضمنها تكاليف النقل إلى دئى المخازن الرئيسية. وبضرب السعر الاستيرادي للمبيد بسعر الصرف التوازني 1233 دينار/دولار نحصل على القئل القيمة الاجتماعية (الظلية) للمبيد 18.7 X1233 = دينار//لتز وهي تمثل القيمة الاجتماعية للتز الواحد من المبيد

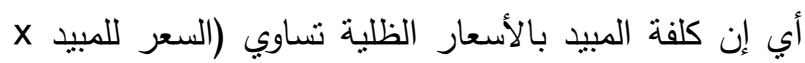

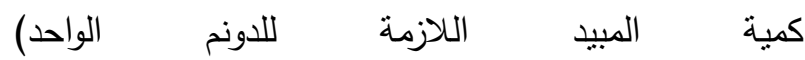

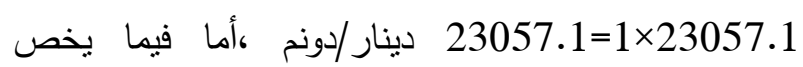
السعر الاستيرادي لوقود الديزل واصل إلى المخازن الرئيسة فيقدر بنحو 92.38 دولار/ برميل أي ما يعادل 716.4

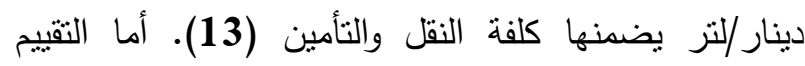
الاجتماعي للموارد المحلية فيختلف عن التقييم الاجتماعي للمدخلات المتاجر بها لإمكانية انتقال السلع المتاجر بها بين العاعي

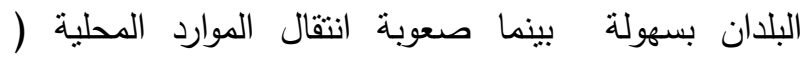
الأرض، العمل، رأس المال) لوجود قيود تحد من حركتها مثل بلن لئل شروط الهجرة، وتكاليف النقل بالنسبة لعنصر العمل، وكذلك لكأل انعدام حركة عنصر الأرض، لذللك يكون التقييم الاجتماعي لمتل هذه الموارد على أساس تكاليف الفرص البديلة (2). فيمكن تقدير الأسعار الاجتماعية وحسابها للموارد المحلية وكما يأتي (2):- 1. بالنسبة لعنصر العمل ولصعوبة انتقاله في المدى القصير للعمل من مشاريع إنتاجية إلى أخرى ، تماته احتساب السعر الدحلي لساعة العمل والبالغة نحو 2500

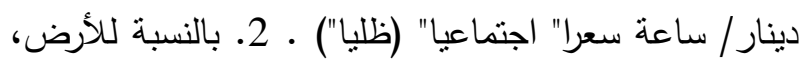
نم احتساب منوسط الإيجار السنوي السائد في سنة استتباط
وبتحويل هذه القيمة إلى العملة المحلية باستعمال سعر التعر الهر

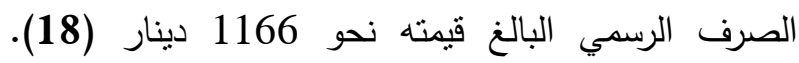
نحصل على السعر الاستيرادي على الحدود بالعملة المحلية

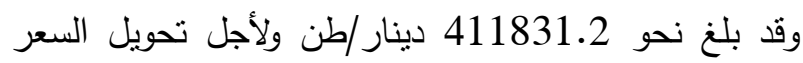
الاستيرادي بسعر الصرف الرسمي إلى السعر التوازني

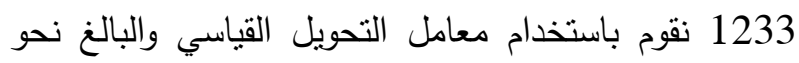
0.945 (18). وهو عبارة عن حاصل قسمه سعر الصرف باستع الرسمي على سعر الصرف التوازني للسنة المعنية. وبالتالي

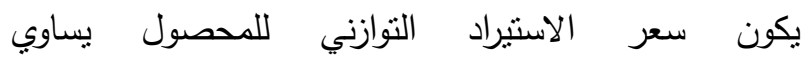

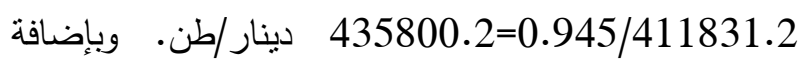
كلفة النقل والتحميل من الميناء إلى المخازن الرئيسة بسعر الصرف التوازني والبالغة نحو 49320 دينار/طن نحصل

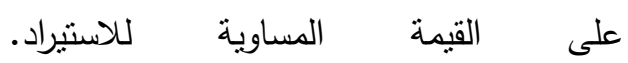

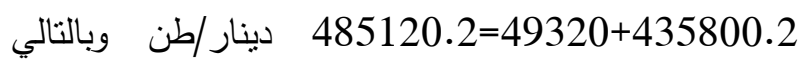
تكون القيمة المساواتية للاستيراد عند باب المزرعة تساوي

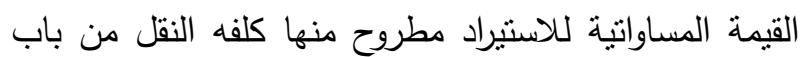
المزرعة إلى المخازن الرئيسة والبالغة نحو 15000 دينار/طن (12). 485120.2 - 15000= 470120.2 دينار/طن وهي تمثل القيمة الاجتماعية (الظلية) للطن من الن النارن محصول القمح لذللك فان سعر الكيلو غرام من القمح يساوي

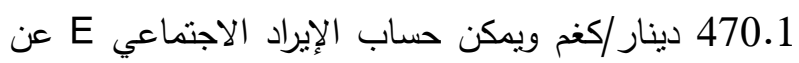
طريق ضرب السعر الظلي لكيلو غرام بمعدل الإنتاجية للاونم

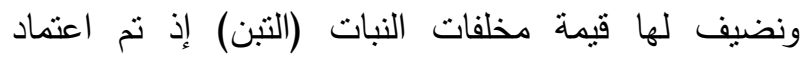
الأسعار الفعلية للتبن والبالغة نحو 20000 دينار/دونم كسعر اجتماعي فنحصل على الإيراد الاجتماعي E وبنفس الطريقة يتم تحويل أسعار باقي المدخلات المتاجر بها من الإيرت الاعي

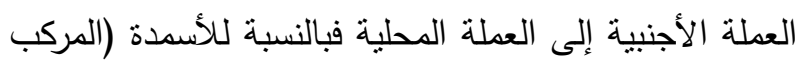
واليوريا) إن كلفة النقل والتحميل للأسمدة من الحدود إلى الى لئل المخازن الرئيسية تتراوح بين 45-55 دولار/طن وكمتوسط 50 دولار /طن (17). أما كلفة النقل من المخازن الرئيسة إلى باب المزرعة نحو 15000دينار/طن (شركات النقل البري). وحيث إن السعر الحدودي للطن الواحد من سماد

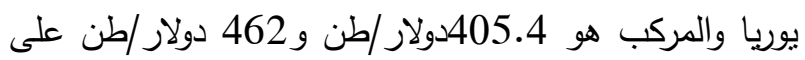
التوالي (19) تكون القيمة المساواتية للاستيراد عند باب ولداب المزرعة للطن من السماد المركب تساوي 678387.5 دينار/ طن وهي تمنل القيمة الاجتماعية (الظلية) للسماد 
نلاحظ من خـلال جدول 7. جاءت تحويلات العائد ا بقيمة موجبة بلغت نحو 291465 إذ يمنل الفرق بين العائد

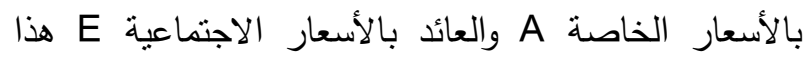
يعني أن العائد بالأسعار الخاصة أعلى من العائد بالأسعار

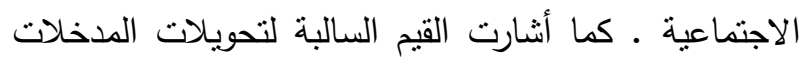
المتاجر بها J التي بلغت قيمتها بنحو 4537 - إلى أن أن

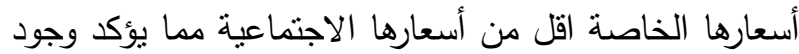
دعم لها ـ أما تحويلات الموارد المحلية K فقد جاءت بقيمة سالبة بلغت نحو - 1000 مما يؤكد وجود إعانة لها أيضا

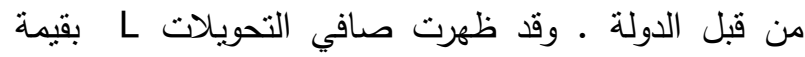

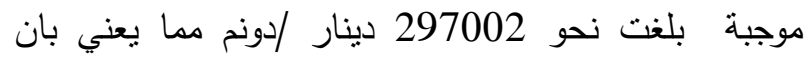

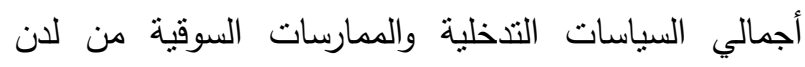
الدولة في نظام المحصول في صالح المُنتج في ذللك العام . قياس الربحية والميزة النسبية لمحصول القمح بحوث 158 للعام 2012: من خلال بعض المؤشرات الاقتصادية الموضحة بالجدول 8. تم قياس الربحية والميزة النسبية

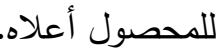
جدول 8. بعض المؤشرات الاقتصادية لمحصول القمح

\begin{tabular}{|c|c|c|}
\hline قيمة المعامل & الصيغة الرياضية للمعامل & نــــوع المـــامـل \\
\hline 2.93 & $\begin{array}{l}\text { PC }=\mathrm{D} / \mathrm{H}=\mathrm{A}-\mathrm{B}- \\
\mathrm{C} / \mathrm{E}-\mathrm{F}-\mathrm{G}\end{array}$ & $\begin{array}{r}\text { معامل الربحية الاجتماعية } \\
\text { (P.C) }\end{array}$ \\
\hline 0.70 & DRC = G/E-F & $\begin{array}{r}\text { معامل كلفة المورد المحلي } \\
\text { (D.R.C) }\end{array}$ \\
\hline$\% 45.36$ & $\begin{array}{l}\mathrm{PSR}=\mathrm{L} / \mathrm{E}=\mathrm{D}-\mathrm{H} / \mathrm{E} \\
* 100\end{array}$ & 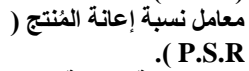 \\
\hline 0.44 & $\mathbf{P C R}=\mathrm{C} / \mathrm{A}-\mathrm{B}$ & معامل الكلفة النسبية \\
\hline
\end{tabular}

7 المصدر :- من إعداد الباحث اعتماداً على نتائج جدول $7 . R$ من خلال نتائج جدول 8. يمكن ملاحظة قيمة معامل الربحية التي بلغت بنحو 2.93 مشيرة إلى إن نظام إنتاج محصول

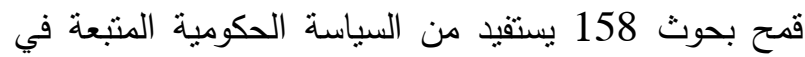
ذلك العام إي انه بوجد دعم للمُنتج من لدن الدولة.وبالنسبة

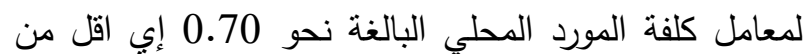

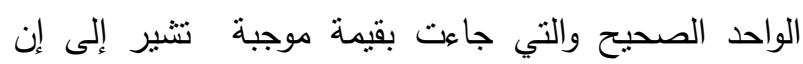
هناك ميزة نسبية بإنتاج محصول قمح بحوث 158 لعام

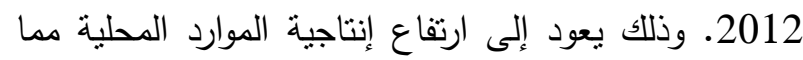

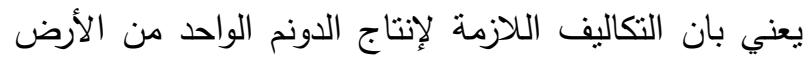

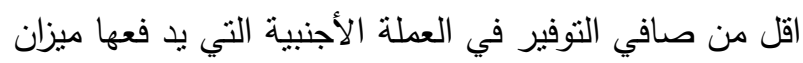

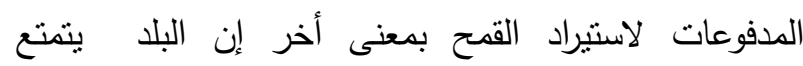
بالمنافسة في أنتاج المحصول وتؤكد قيمة معامل نسبة أعانة

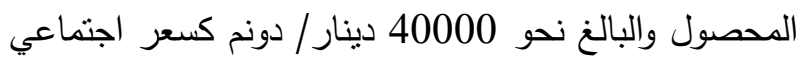
3. المال باحتساب الفائدة على رأس المال والبالغة نحو 10\% لكون العراق يعد من الدول ذات الدخول المتوسطة حسب تقديرات البنك الدولي. 4. أما بالنسبة للعمل الميكانيكي فقد تم احتساب متوسط الأجور السائدة في السنة التي استتبط فيها المحصول والبالغة نحو 15000 دينار/ساعة لتحضير الأرض و 50000 دينار/ساعة للحصاد كسعر اجتماعي جدول 6. ميزانية الحقل لتكاليف عناصر الإتتاج والعائد والريحية الخاصة بالأسعار الاجتماعية لمحصول القمح بحوث 158

\begin{tabular}{|c|c|c|c|}
\hline \multicolumn{4}{|c|}{ لعام 2012} \\
\hline كلفة عناصر & سعر الوحدة الواحدة & عناصر الإنتاج & المدخلات \\
\hline 16453.5 & 470.1 & الأسمدة & المدخلات المتاجر \\
\hline 42595 & 608.5 & 1 - سماد يوريا & بها \\
\hline 27132 & 678.3 & 2 - سماد مركب & \\
\hline 27742.5 & 27742.5 & $\begin{array}{r}\text { مبيدات أدغار) } \\
\text { (دينتر) }\end{array}$ & $\begin{array}{r}\text { Tradable } \\
\text { Inputs }\end{array}$ \\
\hline 25074 & 716.4 & وُقود محركات السقي & (F) \\
\hline 138997 & & & المجموع \\
\hline (نصف السنة) & 40000 & أولا - الأرض (دينار & غالموارد المحلية \\
\hline 15000 & & /سأعة) ويشمل & (G) \\
\hline 100000 & 2500 & 1 - تحضير الأرض & \\
\hline 25000 & 2500 & 2 - السقي & Non Tradable \\
\hline 25000 & 2500 & 3 - العنايةّ بالمحصول & Inputs \\
\hline 12500 & 2500 & 4- الحصاد اليدوي & \\
\hline 5000 & $\begin{array}{c}2500 \\
50000\end{array}$ & 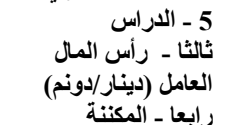 & \\
\hline $\begin{array}{c}60000 \\
100000\end{array}$ & $\begin{array}{l}15000 \\
50000\end{array}$ & 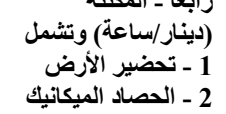 & \\
\hline 362500 & 50149 (التكاليف) & $=362500+138997$ & المجموع \\
\hline 654635 & $634635+20000$ & 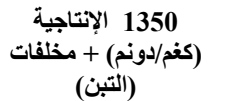 & العائد (E) \\
\hline & $153138=501497-$ & 54635 & $\begin{array}{c}\text { الربحية الخاصة } \\
\text { (H) }\end{array}$ \\
\hline
\end{tabular}

المصدر: من إعداد الباحث بالاعتماد على نشرات مختلفة جدول 7 ـ مصفوفة تحليل السياسة لاونم الواحد من محصول القمح بحوث 158 لعام 2012

\begin{tabular}{|c|c|c|c|c|}
\hline \multirow[t]{2}{*}{ التفاصيل } & \multirow{2}{*}{ الايزي ادودينار } & \multicolumn{2}{|c|}{ الكلفة الكلية } & \multirow[t]{2}{*}{ الربحية } \\
\hline & & المتاجر بها & الموارد المحلية & \\
\hline الاسعار & $\mathbf{A}$ & B & $\mathrm{C}$ & D \\
\hline الخاصة & 946100 & 134460 & 361500 & 450140 \\
\hline الاسعار & $\mathbf{E}$ & $\mathbf{F}$ & G & $\mathbf{H}$ \\
\hline الاجتماعية & 654635 & 138997 & 362500 & 153138 \\
\hline التحويلات & I & $\mathbf{J}$ & $\mathbf{K}$ & $\mathbf{L}$ \\
\hline & 291465 & -4537 & -1000 & 297002 \\
\hline
\end{tabular}

المصدر:حسبث من قبل الباحث اعتمادا على الجدولين 5 و6 
جدول 11. المعاملات الفنية ( Technical coefficients)

\begin{tabular}{|c|c|c|}
\hline الكمية لاونع الواحد & عناصر الإتتاج & المدخلات \\
\hline 35 كفم / دونم & الألبمدة & المدخلات المتاجر بها \\
\hline 70 كفم / دونم على & 1 - سماد يوريا & \\
\hline دفعتين م & & Tradable Inputs \\
\hline 35 كغم/دونم & 2 - سماد مركب & \\
\hline 1 & مبيدات أدغال & \\
\hline 30 & وقود محركات السقي & \\
\hline \multirow[t]{2}{*}{ 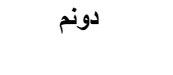 } & أولا - الأرض & \\
\hline & ثثانيا ـ العمل ويشمل & الموارد المحلية غير \\
\hline ساعة / دونم & 1 ـ تحضير الأرض & المتاجز بها \\
\hline ساعة / دونم & 2 ـ السقي & \\
\hline 20 & 3 - العناية بالمحصول & Non Tradable \\
\hline 15 س ساعة / دونم & 4 - الحصاد اليدوي & Inputs \\
\hline 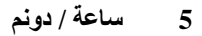 & 5 - 5 الدراس & \\
\hline \multirow[t]{2}{*}{50 ألف دينار للاونم } & ثالثا ــ ـ رأس المال العامل & \\
\hline & رابعا ـ المكنتة وتثشمل & \\
\hline 4 & 1 ـ تحضير الأرض & \\
\hline 2 & 2 ـ الحصاد الميكانيك . . & \\
\hline & الإنتاجية 1800 كفم/دونم & \\
\hline
\end{tabular}

المصدر :المدخلات المتاجر بها اعتمادا على نشرات مختلفة، الموارد

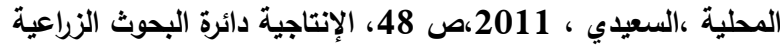
حساب الصف الأول من المصفوفة بالأسعار الخاصة

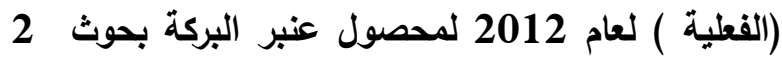
تستخدم الأسعار الخاصة الفعلية عند باب المزرعة في

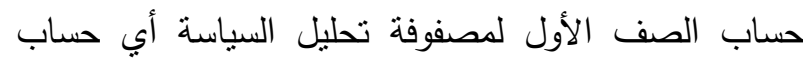
كلفة عناصر الإنتاج والعائد والربحية بصورة مفصلة أما كلفة رأس المال العامل فستقدر بقيمة الفائدة البالغة نحو 8 8 (6). بلغت إنتاجية الدونم الواحد 1800 كغ لمحصول الرز عنبر البركة بحوث 2 في المنطقة المروية (1). كما بلغ سعر الشراء من قبل الدولة بنحو 744 دينار/كغ للعام نفسه (11). وقد تمت إضافة قيمة الدخلفات الثانوية والبالغة نحو

45000 دينار / دونم إلى الإيراد (11) حساب الصف الثاني لمصفوفة تحليل السياسة بالأسعار الاجتماعية لإنتاج محصول الرز عنبر البركة بحوث 2 : بعد أن حُسب الصف الأول من المصفوفة لابد من تعديل

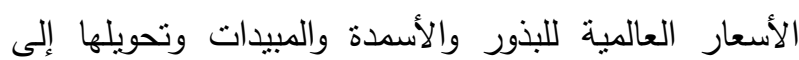
العملة المحلية وبالأسعار الاجتماعية وكما هو موضح

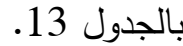

المُنتج المحلي لمحصول القمح أعلاه والبالغة نحو 45.36 \% على وجود أعانة حكومية ولا نوجد ضرائب غير مباشرة

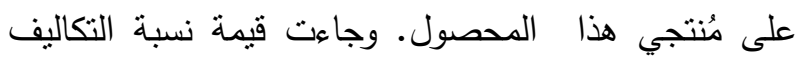
الخاصة اقل من الواحد إذ بلغت نحو 0.44 مشيرة إلى إن لن

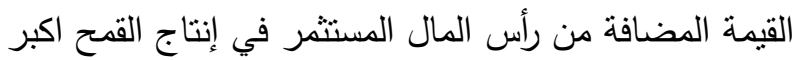
من التكاليف الخاصة وعليه فان الاستثمار في إنتاج القمح بحوث 158 لعام 2012 قد حقق أرباحاً للمستثر المحلي. ويمكن أن نلخص ما جاء أعلاه بالجدول 9. جدول 9. التفسير الاقتصادي لبعض المؤشرات الاقتصادية لمحصول القمح بحوث 158 لعام 2012

\begin{tabular}{|c|c|c|}
\hline الملاحظات & قيمة المعامل & نوع المعامل \\
\hline يوجد دعم للمنتنج المحلي & 2.93 & معامل الربحية الاجتماعية \\
\hline من قبل الدولة. & & (P.C) \\
\hline هناك ميزة نسبية بإنتاج & 0.70 & مععامل كلفة المورد المحلي \\
\hline المحصول أعلاه محليا. & & (D.R.C) \\
\hline وجود أعانة حكومية ولا & $\% 45.36$ & نسبة إعانة المنتنج \\
\hline تولى مُنتجي ألمحصول غير مباشرة & & ( P.S.R) \\
\hline الاستثمار في المحصول & 0.44 & الكلفة النسبية الخاصة \\
\hline أعلاه يحقق أرباحاً للمُنتج & & （P.C.R) \\
\hline
\end{tabular}
مصفوفة تحليل السياسة لمحصول الرز عنبر البركة بحوث 2 لعام

أستتبط هذا المحصول من لان دائرة البحوث الزراعية/ قسم تطوير زراعة الرز عام 2012. وبوساطة فريق عمل هم هن لران (فليح عبد جابر ، ود. سعد فليح حسن، وجساب عبد الحسن وحسين عدنان ، وعبد الكاظم جواد موسى ، وفؤاد إسماعيل خليل) ويجب التعرف على المعاملات الفنية التي تدخل في وحتي عملية أنتاج الوحدة الواحدة من هذا المحصول ولدونم الواحد لغرض حساب مصفوفة تحليل السياسة لهُ إما كلفة رأس المال العامل فتحسب تكاليف الفرص البديلة بتقدير معدلات العائد للاستثمار، ويشير الجدول 10. إلى بعض الصفات الفنية للمحصول أعلاه وكما يأني:

جدول 10. بعض الصفات الفنية لمحصول الرز عنبر البركة بحوث2 2

\begin{tabular}{|c|c|}
\hline عنبر البركة بحوث 2 & المحصول \\
\hline 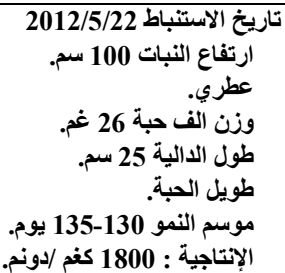 & روقم القرار 6 \\
\hline
\end{tabular}

المصدر: من إعداد الباحث استنادا إلى نثرات مختلفة 
بالحسبان كلفة النقل والثحن وكلفة التامين وكلفة الفقد في الوزن عند التصنيع والبالغة 36\% من سعر الطن الواحد

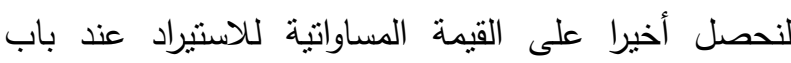
المزرعة والبالغة 453.75 دينار /كغم. وبالطريقة نفسها تحول

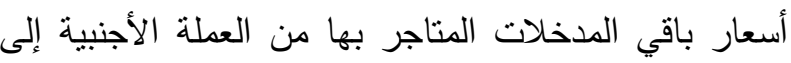

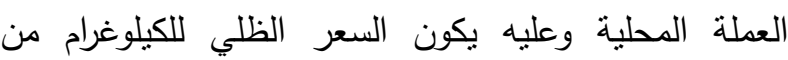
السماد المركب يساوي نحو 678.3 دينار /كغ ولسماد اليوريا

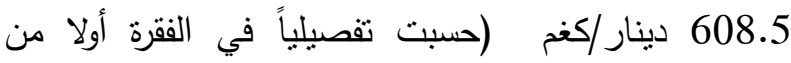
البحث الخاصة بالقمح).أما المبيدات فان القيمة الاجتماعية

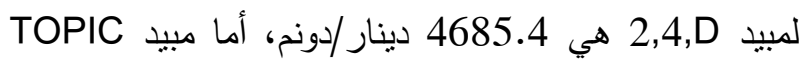
فان القيمة الاجتماعية له هي 23057.1 دينار /دونم (حسبت تفصيلياً في الفقرة أولا).أما فيما يخص الهئه السعر الاستيرادي لوقود الديزل واصل إلى المخازن الرئيسة فيقدر بنحو 92.38 دولار/برميل أي ما يعادل 716.4 دينار/لتر يضمنها كلفة النقل والتأمين وذلك بحسب إحصاءات وزارة بعار النفط الثركة

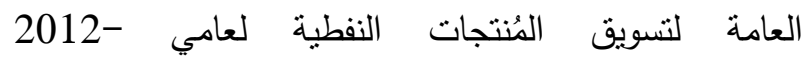
2011(13).أما التقويم الاجتماعي للموارد المحلية فيكون على أساس تكاليف الفرص البديلة(2). وكما هو موضح في الاجناعي

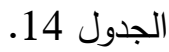

جدول 14. ميزانية الحقل لتكاليف عناصر الإنتاج والعائد والريحية

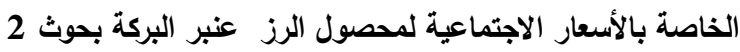

\section{لبعام 2012}

\begin{tabular}{|c|c|c|c|}
\hline كينار/دونم عناصر الإنتاج & سينار/كغم الوحدة الواحدة & عناصر الإنتاج & المدخلات \\
\hline 15881.25 & 453.75 & الأبذورة & المدخلات المتاجر بها \\
\hline 42595 & 608.5 & 1 - سماد يوريا & \\
\hline 23740.5 & 678.3 & 2 - سماد مركب & Tradable Inputs \\
\hline 27742.5 & 27742.5 & مبيدات أدغال & (F) \\
\hline 21492 & 716.4 & وقود محركات السقي & \\
\hline 131451.2 & & & المجموع \\
\hline 20000 (نصف & 40000 & أولا - الأرض (دينار & \\
\hline السنة) السنة & & ثانيا - العمل (دينار /ساعة) & المتاجر بهارد المحلية غير \\
\hline 25000 & & ويشمل & (G) \\
\hline 87500 & 2500 & 1 - تحضير الأرض & \\
\hline 50000 & 2500 & 2 - 2 السقي & Non Tradable \\
\hline 37500 & 2500 & 3 - العناية بالمحصول & Inputs \\
\hline 12500 & 2500 & 4- الحصاد اليدوي & \\
\hline 5000 & $\begin{array}{c}2500 \\
50000\end{array}$ & 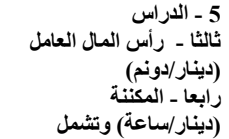 & \\
\hline 100000 & $\begin{array}{l}15000 \\
50000\end{array}$ & 1 - 1 - تحضير المضيكانيك & \\
\hline 397500 & 52895 (التكاليف) & $2=397500+131451.2$ & 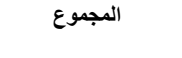 \\
\hline 861750 & $45000+816750$ & (كغم/دونم) + مخلفات & العائد (E) \\
\hline \multicolumn{3}{|c|}{$332798.8=528951.2-861750$} & الربحية الخاصة (H) \\
\hline
\end{tabular}

المصدر:سعر البذور (الثركة العامة لتجارة الحبوب) ، أسعار الأسمدة (الثركة

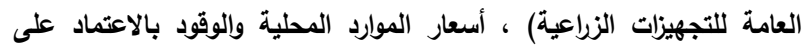
نشرات مختلفة
جدول 12. ميزانية الحقل لتكاليف عناصر الإنتاج والعائد والربحية الخاصة بالأسعار الخاصة لمحصول الرز عنبر البركة بحوث 2 لعام

2012

\begin{tabular}{|c|c|c|c|}
\hline كلفة عناصر & سينار/كغر الوحدة الواحدة & عناصر الإنتاج & المدخلات \\
\hline 26040 & 744 & الألبمدة & المدخلات المتاجر \\
\hline 35000 & 500 & 1 - سماد يوريا & بها \\
\hline 16800 & 480 & 2 - سماد مركب & \\
\hline 30000 & 30000 & مبيدات أدغال & Tradable \\
\hline 22500 & $\mathbf{7 5 0}$ & وقُود محركات & $\begin{array}{l}\text { Inputs } \\
\text { (B) }\end{array}$ \\
\hline 130340 & & & المجموع \\
\hline 20000 (نصفة & 40000 & 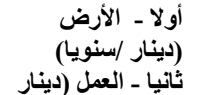 & غير المتاجر بهاية \\
\hline 25000 & & 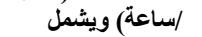 & (C) \\
\hline 87500 & 2500 & 1 ـ 1 - تحضير الأرض & \\
\hline 50000 & 2500 & 2 - 2 - السقي & Non Tradable \\
\hline 37500 & 2500 & 3 - 3 - العناية & Inputs \\
\hline 12500 & 2500 & بالمحصول & \\
\hline 4000 & $\begin{array}{c}2500 \\
50000\end{array}$ & 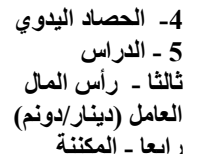 & \\
\hline 100000 & $\begin{array}{l}15000 \\
50000\end{array}$ & 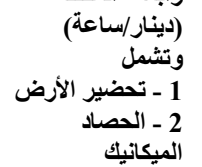 & \\
\hline 396500 & = 526840 (التكاليف) & $396500+130340$ & المجموع \\
\hline 1384200 & $45000+1339200$ & $\begin{array}{c}1800 \\
\text { (كفم/دونم) +الإجتاجية } \\
\text { مخلفات }\end{array}$ & العائد (A) \\
\hline \multicolumn{3}{|c|}{$857360=526840-1384200$} & الربحية الخاصة (D) \\
\hline
\end{tabular}

المصدر:سعر البذور (الثركة العامة لتجارة الحبوب) ، أسعار الأسمدة

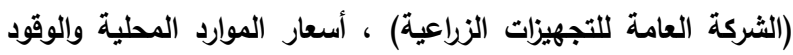
بالاعتماد على نشرات مختلفة

جدول 13. تعديل الأسعار العالمية إلى القيمة المساواتية للاستيراد عند باب المزرعة لعام 2012

\begin{tabular}{|c|c|}
\hline 5 516 دولار / طن & + سعر تصدير الطن الواحد من الرز العالمي \\
\hline 40 دولار / طن & كلفة النقل و التامين وصولا إلى الميناء " الحدود" \\
\hline 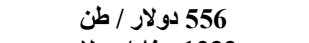 & = السعز الاستيرادي للبلد × \\
\hline 1233 دينار/ دولار & سعر الصرف التوازني ( دينار/ دولار) \\
\hline ( 685548 دينار / طن & = سعر الاستيراد بّالدينار العراقي \\
\hline 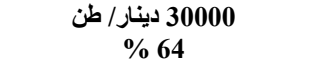 & + كلفة النقل والتحميل من الميناء إلى المخازَن الرئيسة \\
\hline $\begin{array}{c}246797.2=685548 \\
\text { دينار/طن } 0.36\end{array}$ & - كلفة الفقد في الوزنّ عند التصنيع \\
\hline (468751 دينار/ طن & = القيمة المساو اتية للاستيراد \\
\hline (15000 دينار / طن & تكاليف النقل من باب المزرعة إلى المخازر \\
\hline د/كغ & \\
\hline
\end{tabular}

المصدر:- حسبت من لان الباحث بالاعتماد على المصادر رقم 18,12,5. حيث اعتمد السعر العالمي لأفضل أنواع الرز التايلندي لعام 2012 والذي بلغ متوسطه نحو 516 دولار/طن (12). وتم تعديل هذا السعر إلى سعر الصرف التوازني للدينار العراقي مقابل الدولار الأمريكي المحدد بوساطة المزاد العلني للعملات

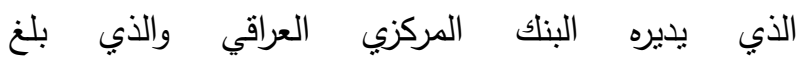
1233دينار/دولار كمتوسط لعام 2012 (18). مع الأخذ 
المتبعة في ذلك العام إي انه يوجد دعم للمُنتج من لدن الدولة وبالنسبة لمعامل كلفة المورد المحلي البالغة نحو دئه 0.54 إي اقل من الواحد الصحيح والتي جاءت بقيمة موجبة تثير إلى إن هناك ميزة نسبية بإنتاج محصول الرز عند الفيح البركة بحوث 2 لعام 2012.وذللك يعود إلى ارتفاع إنتاجية الموارد المحلية مما يعني بان التكاليف اللازمة لإنتاج الدونم الواحد من الأرض اقل من صافي التوفير في العملة الأجنبية

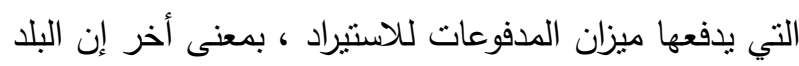

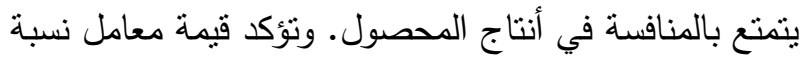
أعانة المُنتج المحلي لمحصول الرز عنبر البركة بحوث 2 بلمبه

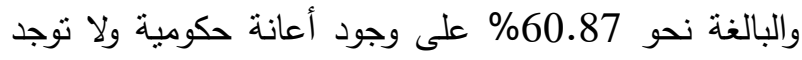
ضرائب غير مباشرة على مُنتجي هذا المحصول. وأخيرا

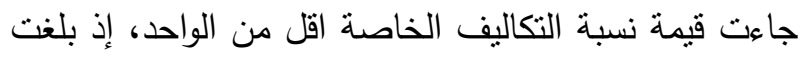
نحو 0.31 مشيرة إلى أن القيمة المضافة من رأس المال

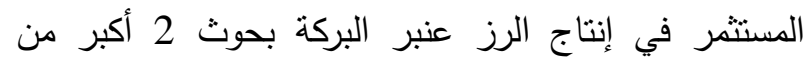
التكاليف الخاصة، وعليه فان الاستثمار في إنتاج المحصول أعلاه لعام 2012 قد حقق أرباحا لا باس بها للمستثر المحلي ويمكن أن نلخص ما جاء أعلاه بالجدول 17. جدول 17. التفسير الاقتصادي لبعض المؤشرات الاقتصادية لمحصول الرز عنبر البركة بحوث 2 عام

2012

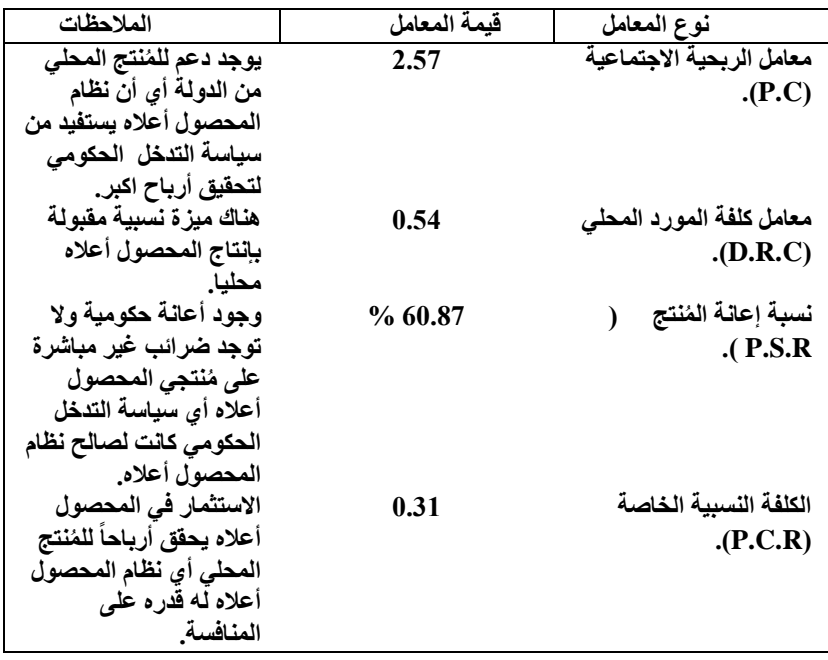

المصدر : من عمل الباحث اعتمادا على جدول 16

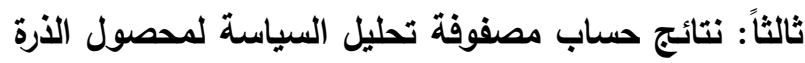
الصفراء التركيبي فجر 1 لعام 2012 أستتبط هذا المحصول من دائرة البحوث الزراعية / قسم بحوث الذرة الصفراء والبيضاء عام 2012. وهو محصول تركيبي خريفي مستتبط محلياً ويوصى بزراعته في المناطق الوسطى والثمالية للبلد

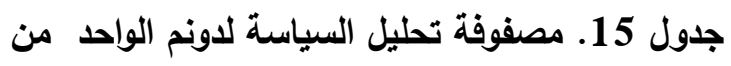

\section{محصول الرز عنبر البركة بحوث 2 لعام 2012}

\begin{tabular}{|c|c|c|c|c|}
\hline \multirow[t]{2}{*}{ التفاصيل } & \multirow{2}{*}{ /الايراد/دينار } & \multicolumn{2}{|c|}{ الكلفة الكلية } & \multirow[t]{2}{*}{ الربحية } \\
\hline & & المتاجر بهات & الموارد المحلية & \\
\hline الخاصعة & $\begin{array}{c}A \\
1384200\end{array}$ & $\begin{array}{c}\text { B } \\
130340\end{array}$ & $\begin{array}{c}C \\
396500\end{array}$ & $\begin{array}{c}\text { D } \\
857360\end{array}$ \\
\hline الاجتماعية & $\begin{array}{c}E \\
861750\end{array}$ & $\begin{array}{c}F \\
131451.2\end{array}$ & $\begin{array}{c}\mathbf{G} \\
397500\end{array}$ & $\begin{array}{c}\text { H } \\
\mathbf{3 3 2 7 9 8 . 8}\end{array}$ \\
\hline التحويلات & $\begin{array}{c}\text { I } \\
522450\end{array}$ & $\begin{array}{c}\mathrm{J} \\
-1111.2 \\
\end{array}$ & $\begin{array}{c}K \\
-1000 \\
\end{array}$ & $\begin{array}{c}\text { L } \\
\mathbf{5 2 4 5 6 1 . 2}\end{array}$ \\
\hline
\end{tabular}

المصدر:حسبت من قبل الباحث اعتمادا على الجدولين 12 و 14 نلاحظ من جدول 15. جاءت تحويلات العائد ا بقيمة موجبة بلغت نحو 522450 إذ يمثل الفرق بين العائد بالأسعار الخاصة A والعائد بالأسعار الاجنماعية E.هذا يعني أن العائد بالأسعار الخاصة أعلى من العائد بالأسعار

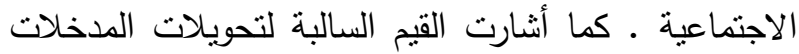
المتاجر بها J التي بلغت قيمتها بنحو 1111.2- إلى ألى أن

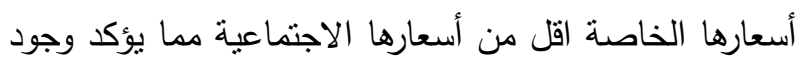
دعم لها. إما تحويلات الموارد المحلية K فقد جاءت بقيمة سالبة أيضا بلغت نحو 1000- مما يؤكد وجود إعانة لها أيضا من الدولة ـ وقد ظهرت صافي التحويلات L بقيمة موجبة بلغت نحو 524561.2 دينار/دونم مما يعني بان أجمالي السياسات التذخلية والممارسات السوقية من الدولة في نظام المحصول في صالح المُنتج في ذلك العام . قياس الريحية والميزة النسبية لمصصول الرز عنبر البركة بحوث2 عام 2012: من خلال بعض المؤشرات الاقتصادية الموضحة بالجدول 16. نم قياس الربحية والميزة النسبية للمحصول أعلاه.

جدول 16. بعض المؤثرات الاقتصادية لمحصول الرز عنبر البركة بحوث2 عام 2012

\begin{tabular}{|c|c|c|}
\hline قيمة المعامـل & الصيغة الرياضية للمعامل & نـــوع المـعـامـل \\
\hline 2.57 & $\begin{array}{l}\mathrm{PC}=\mathrm{D} / \mathrm{H}=\mathrm{A}-\mathrm{B}- \\
\text { C/E-F-G }\end{array}$ & معامل الربحية الاجتماعية \\
\hline 0.54 & DRC $=$ G/E-F & معامل كلقة المورد المحلي \\
\hline$\% 60.87$ & $\begin{array}{l}\mathrm{PSR}=\mathrm{L} / \mathrm{E}=\mathrm{D}-\mathrm{H} / \mathrm{E} \\
* 100\end{array}$ & معامل نسبة إعانة المُنتج ) (D.R.C) \\
\hline 0.31 & PCR $=$ C/A-B & الخاصلة الكلفة النسبية \\
\hline
\end{tabular}

المصدر :- من إعداد الباحث اعتماداً على نتائج جدول 15 من نتائج جدول 16. يمكن ملاحظة قيمة معامل الربحية

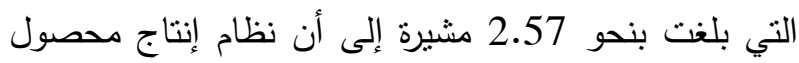
الرز عنبر البركة بحوث 2 يستقيد من السياسة الحكومية 
حساب الصف الأول من المصفوفة بالأسعار الخاصة

(الفعلية ) لعام 2012 لمحصول الذرة التركيبي فجر 1 (الفنس بلغت إنتاجية الدونم الواحد 2901 كغم لهحصول الذرة الصفراء التركيبي فجر 1 (1). في المنطقة الثمالية كما بلغ سعر الثراء من الدولة بنحو 646 دينار/كغ للعام نفسه(11). وقد أضيفت قيمة المخلفات الثانوية والبالغة نحو 30000 دينار/كغ إلى الأيراد (15).أما كلفة رأس المال

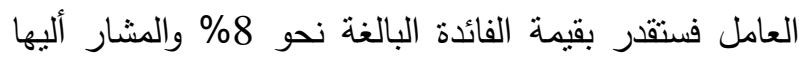

$$
\text { سابقا (6). وكما يأتي: }
$$

جدول 20. ميزانية الحقل لتكاليف عناصر الإنتاج والعائد والربحية الخاصة بالأسعار الخاصة لمحصول الذرة الصفراء

\begin{tabular}{|c|c|c|c|}
\hline 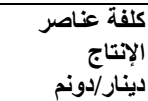 & سينار/كفم الوحدة الواحدة & عناصر الإنتاج & المدخلات \\
\hline 4522 & 646 & الأبذدة & المدخلات المتاجر \\
\hline 50000 & 500 & 1 - سماد يوريا & بها \\
\hline 24000 & 480 & 2 - سماد مركب & \\
\hline 45000 & 30000 & مبيدات أدغال & Tradable \\
\hline 18750 & 750 & وقود محركات السقي & $\begin{array}{l}\text { Inputs } \\
\text { (B) }\end{array}$ \\
\hline 142272 & & & المجموع \\
\hline $\begin{array}{l}20000 \\
\text { (نصف السنة) }\end{array}$ & 40000 & 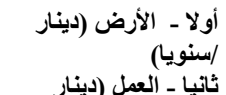 & غير المتاحد المحلية \\
\hline 10000 & & /سأعة) ويشمل & (C) \\
\hline 35000 & 2500 & 1 ـ تحضير الأرض & \\
\hline 25000 & 2500 & 2 - السقي & Non Tradable \\
\hline 25000 & 2500 & 3 ـ العنايةً بالمحصول & Inputs \\
\hline 25000 & 2500 & 4- الحصاد اليدوي & \\
\hline 3200 & $\begin{array}{c}2500 \\
40000\end{array}$ & 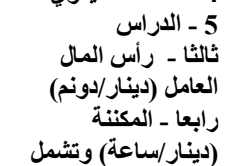 & \\
\hline 100000 & $\begin{array}{l}15000 \\
50000\end{array}$ & 1 - الحصنير الميكاتيك & \\
\hline 303200 & 44547 (التكاليف) & $=303200+142272$ & المجموع \\
\hline 1904046 & $30000+1874046$ & 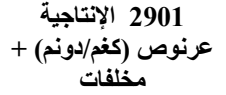 & العائد (A ) \\
\hline & \multicolumn{2}{|c|}{ مخلفات 1904046} & $\begin{array}{l}\text { الربحية الخاصة } \\
\text { (D) }\end{array}$ \\
\hline
\end{tabular}

المصدر:سعر البذور (الشركة العامة لتجارة الحبوب) ، أسعار الأسمدة

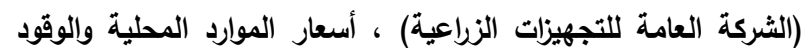
بالاعتماد على نشرات مختلفة حساب الصف الثاني لمصفوفة تحليل السياسة بالأسعار الاجتماعية لإنتاج الذرة الصفراء التركيبي فجر 1 لعام 2012 بعد أن جرى حساب الصف الأول من المصفوفة

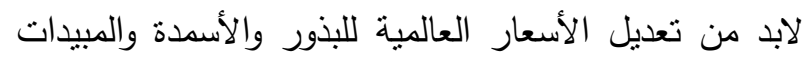

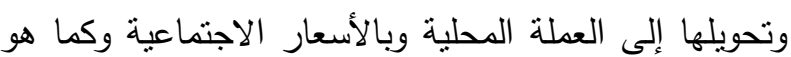
موضح بالجدول 21.

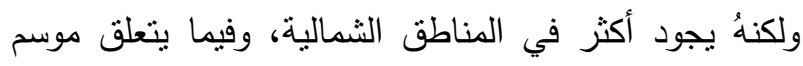
الزراعة فهو يصلح للموسم الخريفي وكذلك يمكن زراعته في الموسم الربيعي عند بداية شهر آذار وهو شبه مقاوم للحشرات

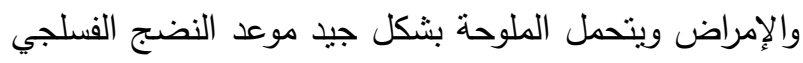
108 يوم وكمية الحاصل (عرنوص) 2025 كغم/دونم في مناطق الوسط 2901 كغم/دونم في مناطق الثمال.ولغرض ولهرئ حساب مصفوفة تحليل السياسة للحصصول المستتبط أعلاه لابد من التعرف على المعاملات الفنية التي تدخل في عملية أنتاج الوحدة الواحدة من المحصول ولدونم الواحد. وفيما يتعلق بكلفة رأس المال العامل حسبث تكاليف الفرص البديلة

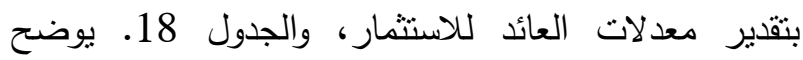
بعض الصفات الفنية للمحصول أعلاه وكما يأتي: جدول 18. بعض الصفات الفنية لمحصول الذرة الصفراء

\begin{tabular}{|c|c|}
\hline \multicolumn{2}{|c|}{ التركيبي فجر 1} \\
\hline التركيبي فجر 1. & المحصول \\
\hline تاريخ الاستتباط 2012/3/5 & رقم كتاب الاعتماد 43 \\
\hline ارتفاع النبات 149.33 سم. & مو اصفاته \\
\hline وزن الف حبة 257.56 غم. & $\bullet$ \\
\hline طول الكوز 15.42 سم. & - \\
\hline الإنتاجية: 2091 عرنوص كغم/ & - \\
\hline دونم & \\
\hline
\end{tabular}

جدول 19. المعاملات الفتية ( Technical coefficients)

لمحصول الذرة الصفراء التركيبي فجر 1 في المنطقة الثمالية

\begin{tabular}{|c|c|c|}
\hline الكمية لدونم الواحد & عناصر الإنتاج & المدخلات \\
\hline \multirow[t]{2}{*}{7 كغم / دونم } & البذور & \\
\hline & 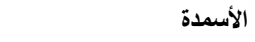 & المدخلات المتاجر بها \\
\hline 100 كفم / دونم على & 1 - سماد يوريا & \\
\hline دفقتين ا با & & Tradable Inputs \\
\hline 50 & 2 - سماد مركب & \\
\hline 1.5 & مبيدات أدغال & \\
\hline 25 & وقود محركات السقي & \\
\hline \multirow[t]{2}{*}{ 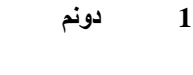 } & أولا - الأرض & \\
\hline & ثانيا ـ العمل ويثمل & الموارد المحلية غير \\
\hline 4 & 1 ـ تحضير الأرض & المتاجز بها \\
\hline 14 & 2 - السقي & \\
\hline 10 & 3 - العنايةً بالمحصول & Non Tradable \\
\hline 10 & 4 - الجني اليذوي & Inputs \\
\hline 10 & 5 - تنظيف الكوالح & \\
\hline \multirow[t]{2}{*}{40 ألف دينار للاونم } & ثاثثا ــــ رأس المال العامل & \\
\hline & رابعا ـ المكنتة وتثمل & \\
\hline 4 ساعة / دونم & 1 - تحضير الأرض & \\
\hline \multirow[t]{3}{*}{ ساعة / دونم } & 2 - الحصاد الميكانيك & \\
\hline & الإنتاجية 2901 (عرنوص) & \\
\hline & كفم/دونم & \\
\hline
\end{tabular}

المصدر :المدلات المتاجر بها اعتمادا على نثرات مختلفة ، الموارد المحلية ،وجدان ، 2011،ص 75، الإنتاجية دائرة البحوث الزراعية 
أما التقويم الاجتماعي للموارد المحلية فيكون على أساس. تكاليف الفرص البديلة (2). وكما هو موضح في الجدول

جدول 22. ميزانية الحقل لتكاليف عناصر الإنتاج والعائد والريحية الخاصة بالأسعار الاجتماعية لمحصول الذرة

الصفراء التركيبي فجر 1 لعام 2012

\begin{tabular}{|c|c|c|c|}
\hline كالفّةُ عناصر & سينار/كغن & عناصر الإنتاج & المدخلات \\
\hline 3017 & 431 & الألذمدر & المدخلات المتاجر \\
\hline 60850 & 608.5 & 1 - سماد يوريا & بها \\
\hline 33915 & 678.3 & 2 - سماد مركب & \\
\hline 41613.7 & 27742.5 & مبيدات أدغال & Tradable \\
\hline 17910 & 716.4 & وقود محركات السقي & $\begin{array}{l}\text { Inputs } \\
\text { (F) }\end{array}$ \\
\hline 157305.7 & & & المجموع \\
\hline 20000 & 40000 & أولا - الأرض (دينار & غالموارد المحلية \\
\hline 10000 & & /سأعة) و العمل (دينار & $\begin{array}{l}\text { غير المتاجر بها } \\
\text { (G) }\end{array}$ \\
\hline 35000 & 2500 & 1 - تحضير الأرض & \\
\hline 25000 & 2500 & 2 - 2 - السقي & Non Tradable \\
\hline 25000 & 2500 & 3 - العناية بالمحصول & Inputs \\
\hline 25000 & 2500 & 4- الحصاد اليدوي & \\
\hline 4000 & $\begin{array}{c}2500 \\
40000\end{array}$ & 5 ـ العامثا - رأس المال & \\
\hline $\begin{array}{l}60000 \\
100000\end{array}$ & $\begin{array}{l}15000 \\
50000\end{array}$ & 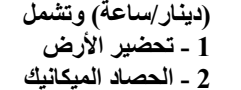 & \\
\hline 304000 & 461305 (التكاليف) & $=304000+157305.7$ & المجموع \\
\hline 1280331 & $30000+1250331$ & $\begin{array}{c}\text { (كف/دونم) + مخلفات } 2901 \text { الإنتاجية) } \\
\text { (عرنة) }\end{array}$ & العائد (E) \\
\hline \multicolumn{3}{|c|}{$819025.3=461305.7-1280331$} & الربحية الخاصة \\
\hline
\end{tabular}

المصدر:سعر البذور (الثركة العامة لتجارة الحبوب) ، أسعار الأسمدة

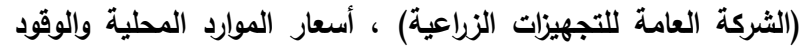
بالاعتماد على نشرات مختلفة جدول 23. مصفوفة تحليل السياسة لاونم محصول الذرة الصفراء التركيبي فجر 1 لعام 2012

\begin{tabular}{|c|c|c|c|c|}
\hline \multirow[t]{2}{*}{ التفاصيل } & \multirow{2}{*}{ /الاير/د/دينار } & \multicolumn{2}{|c|}{ الكلفة الكلية } & \multirow[t]{2}{*}{ الربحية } \\
\hline & & المدخلات المتاجر بـ & الموارد المحلية & \\
\hline الاسعار & $\mathbf{A}$ & B & $\mathbf{C}$ & D \\
\hline الخاصة & 1904046 & 142272 & 303200 & 1458574 \\
\hline الاسعار & $\mathbf{E}$ & $\mathbf{F}$ & G & $\mathbf{H}$ \\
\hline الاجتماعية & 1280331 & 157305.7 & 304000 & 819025.3 \\
\hline التحويلات & $\begin{array}{c}\text { I } \\
623715\end{array}$ & $\underset{-15033.7}{\mathbf{J}}$ & $\begin{array}{c}\mathbf{K} \\
-800\end{array}$ & $\begin{array}{c}\mathbf{L} \\
\mathbf{6 3 9 5 4 8 . 7}\end{array}$ \\
\hline
\end{tabular}

المصدر:حسبت من قبل الباحث اعتمادا على الجدولين 20 و 22. نلاحظ من الجدول 23. جاءت تحويلات العائد ا بقيمة موجبة بلغت نحو623715 إذ يمثل الفرق بين العائد

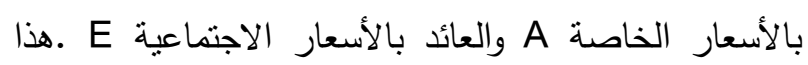

جدول 21. تعديل الأسعار العالمية إلى القيمة المساواتية للاستيراد عند باب المزرعة لعام 2012

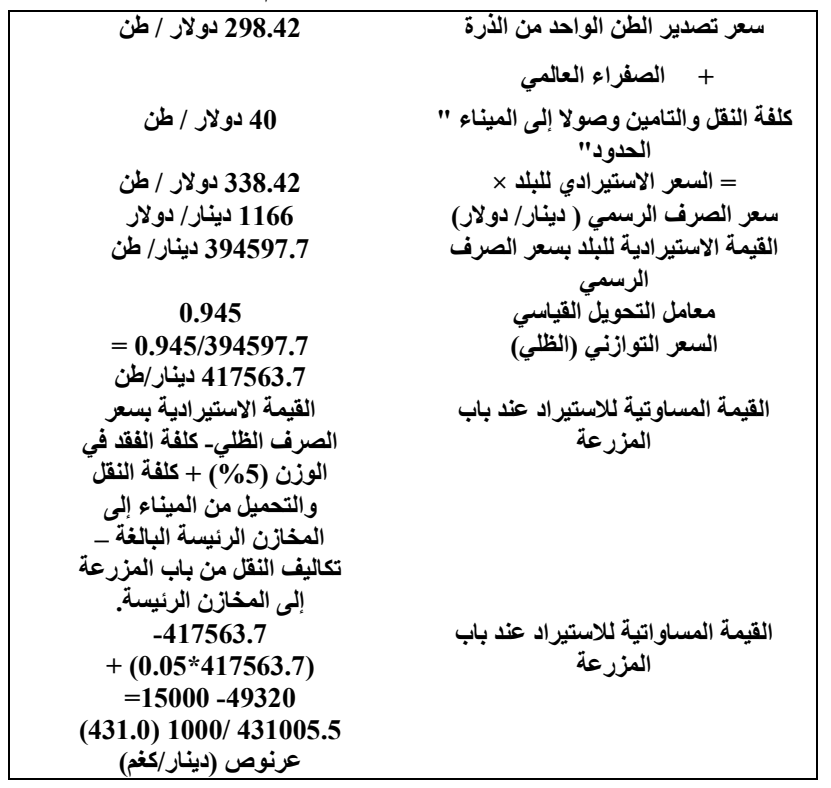

5، المصدر:- حسبت من لان الباحث بالاعتماد على المصادر رقم 11، إذ أعتمد السعر العالمي لأفضل أنواع الذرة الصفراء لعام 2012 والذي بلغ منوسطه نحو 298.42 دولار/طن (18). وجرى تعديل هذا السعر إلى سعر الصرف التوازني للاينار العراقي مقابل الدولار الأمريكي المحدد بوساطة المزاد العلني للعملات الذي يديره البنك المركزي العراقي والذي بلغ 1233

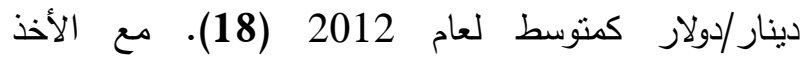
بالحسبان كلفة النقل والثحن وكلفة التامين وكلفة الفقد في الوزن والبالغة 5\% من سعر الطن الواحد، لنحصل أخيرا

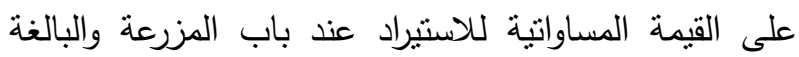

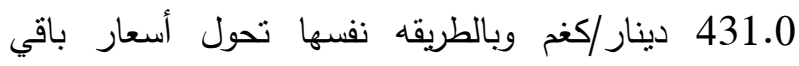
المدخلات المتاجر بها من العملة الأجنبية إلى العملة المحلية

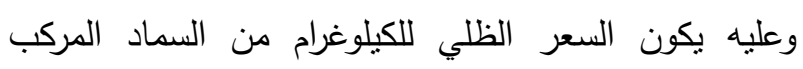
يساوي نحو 678.3 دينار/كغم ولسماد اليوريا 608.5 دينار/كغم (حسبت تفصيلياً في الفقرة أولا) أما المبيدات فان النيار القيمة الاجتماعية لمبيد 2,4,D هي 4685.4 دينار/دونم ومبيد 23057.1 دينار/كغم (حسبت تقصيلياً في الفقرة أولا). أما فيما يتعلق السعر الاستيرادي لوقود الديزل واصل إلى المخازن الرئيسة فيقدر بنحو 92.38 دولار/برميل أي ما يعادل 716.4 دينار/ لتز يضمنها كلفة النقل والتأمين وذلك حسب إحصاءات وزارة النفط الثركة العامة لتسويق المنتجات النفطية لعام 2011-2012 (13) 
المحصول. وأخيرا جاءت قيمة نسبة التكاليف الخاصة اقل لطئ من الواحد إذ بلغت نحو 0.17 مشيرة إلى إن القيمة المضافة من رأس المال المستثمر في إنتاج الذرة الصفراء التركيبي فجر 1 اكبر من التكاليف الخاصة. وعليه فان الاستثمار في

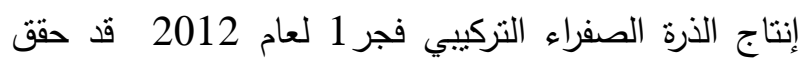

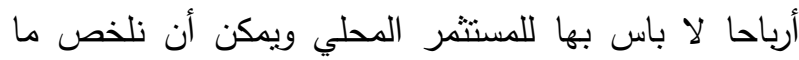

$$
\text { جاء أعلاه بالجدول } 25 .
$$

جدول 25. التفسير الاقتصادي لمعامل الريحية و معاملات الميزة النسبية لمحصول الذرة الصفراء التركيبي فجر 1 لعام

\section{2}

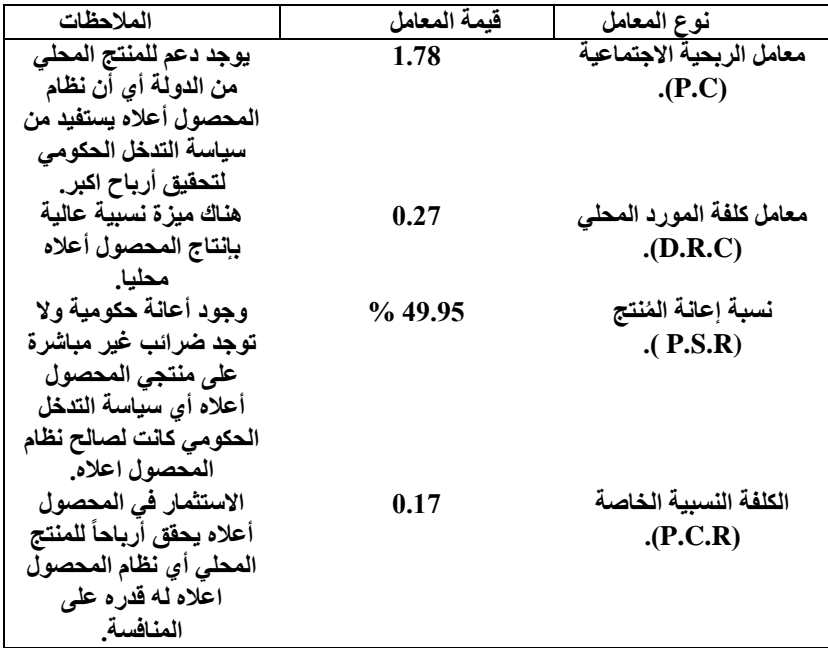

المصدر : من عمل الباحث اعتمادا على جدول 24

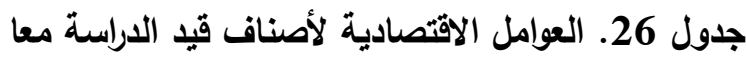

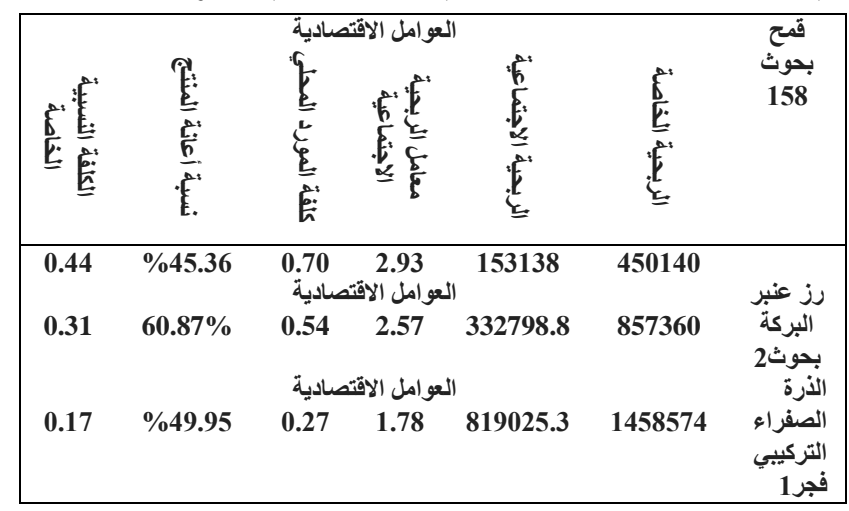

المصدر : من عمل الباحث استنادا إلى جدول 24,23,16.15,8,7 أولا: محصول القمح بحوث 158 لعام 2012 بلغ قيمة

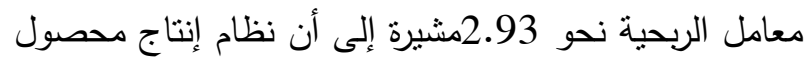
قمح بحوث 158 أي انه يوجد دعم للمنتج من لدن الدولة، بلغ معامل كلفة المورد المحلي نحو 0.70 أثنار إلى إنه بنه يمكن أن يكون هناك ميزة نسبية مقبولة بإنتاج المحصول

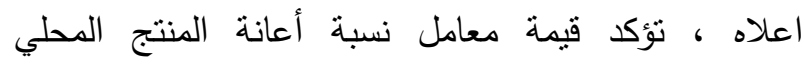
لمحصول القمح أعلاه والبالغة نحو 45.36 \% على على وجود
يعني أن العائد بالأسعار الخاصة أعلى العلى من العائد بالأسعار

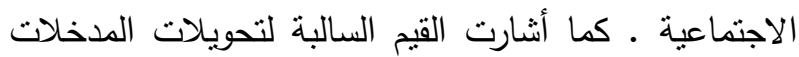
المتاجر بها J التي بلغت قيمتها بنحو 15033.7- إلى ألى أن

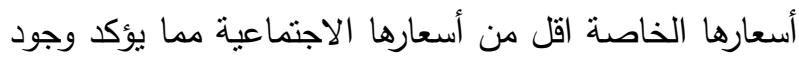
دعم لها. إما تحويلات الموارد المحلية K فقد جاءت بقيمة

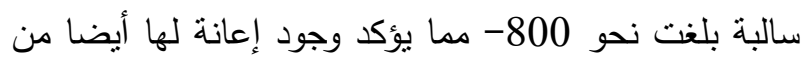

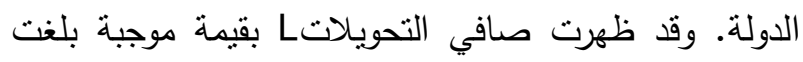

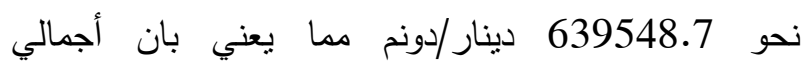
السياسات التدخلية والممارسات السوقية من الدولة في نظام المحصول في صالح المنتج في ذلك العام • قياس الريحية والميزة النسبية لمحصول الذرة الصفراء التركيبي فجر 1 لعام 2012 من خلال بعض المؤشرات الاقتصادية الموضحة بالجدول 24. تم قياس الربحية والميزة النسبية للمحصول أعلاه جدول 24.معامل الربحية و معاملات الميزة النسبية

لمحصول الذرة الصفراء التركيبي فجر 1 عام 2012

\begin{tabular}{|c|c|c|}
\hline قِيمةٌ المعامـل & الصيغة الرياضية للمعامل & نـــوع المـعـامـل \\
\hline 1.78 & $\begin{array}{l}\mathbf{P C}=\mathrm{D} / \mathrm{H}=\mathrm{A}-\mathrm{B}- \\
\mathrm{C} / \mathrm{E}-\mathrm{F}-\mathrm{G}\end{array}$ & معامل الربحية الاجتماعية \\
\hline 0.27 & $\mathrm{DRC}=\mathrm{G} / \mathbf{E}-\mathbf{F}$ & معامل كلفة المورد المحطي \\
\hline$\% 49.95$ & $\begin{array}{l}\mathrm{PSR}=\mathrm{L} / \mathrm{E}=\mathrm{D}-\mathrm{H} / \mathrm{E} \\
* 100\end{array}$ & معامل نسبة إعانة المُنتج (P.S.C) \\
\hline 0.17 & PCR $=$ C/A-B & الخاصلة (الكلفة النسبية \\
\hline
\end{tabular}

المصدر :- من إعداد الباحث اعتماداً على نتائج جدول 23 من نتائج جدول 24. يمكن ملاحظة قيمة معامل الربحية

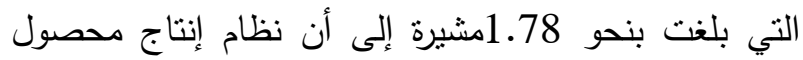

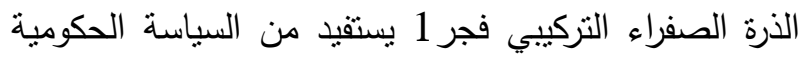
المتبعة في ذللك العام أب انه يوجد دعم للمنتج من للن

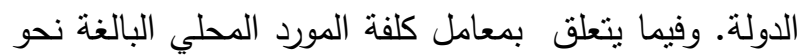
0.27 أب اقل من الواحد الصحيح والتي جاءت بقيمة موجبة تتير إلى إن هناك ميزة نسبية بإنتاج محصول الذرة الصفراء التركيبي فجر 1 لعام 2012 وذللك يعود إلى ارتفاع إنتاجية

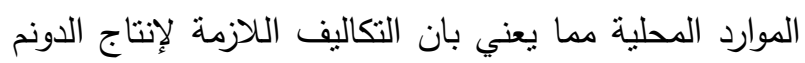

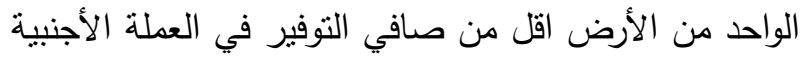

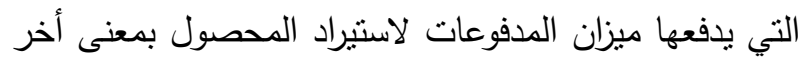

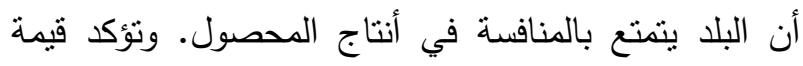
معامل نسبة أعانة المنتج المحلي لمحصول الذرة الصفراء التركيبي فجر 1 أعلاه والبالغة نحو 49.95 \% على العي وجود أعانة حكومية ولا توجد ضرائب غير مباشرة على منتجي هذا 
الصفراء أعلاه والبالغة نحو 49.95\% وجود أعانة حكومية ولا توجد ضرائب غير مباشرة على منتجي هذا المحصول.

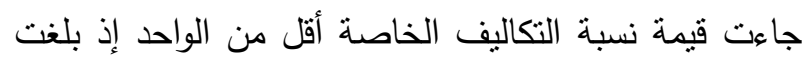
نحو 0.17 مشيرة إلى إن القيمة المضافة من رأس المال

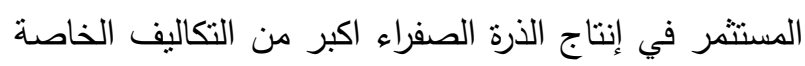
وعليه فان الاستتمار في إنتاج محصول الذرة الصفراء التزكيبي (فجر 1) يمكن أن يحقق أرباحا لا باس بها للمستثمر

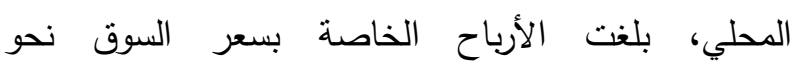
1458574 دينار وهي موجبة وهذا يعني أن محصول الذرة الصفراء التركيبي (فجر 1) رابح ،هنالك دعم للمدخلات

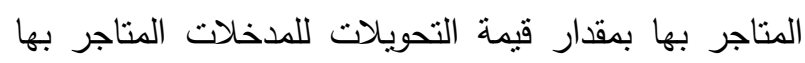

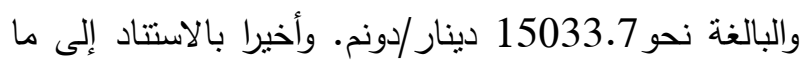
جاء أعلاه والجدول 26 ومن المقارنة بين محاصيل قيد الدراسة وهي (القمح بحوث158 والثلب عنبر البركة بحوث2 والذرة الصفراء التركيبي فجر 1) ، نلاحظ تفوق الذرة الصفراء التركيبي فجر 1 على المحاصيل أعلاه على وفق قيم

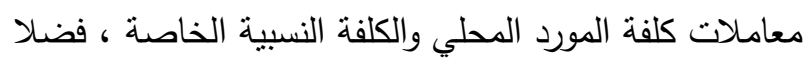

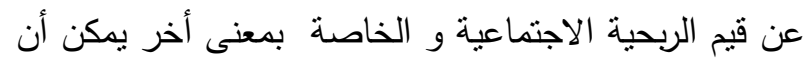
يكون المحصول أعلاه هو المحصول الأكثر ميزه نسبيه في الاجئه

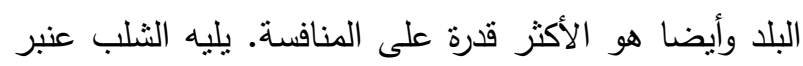
البركة بحوث2 واخيرا محصول القمح بحوث 158. بالاستتاد إلى ما توصلت إليه الدراسة من نتائج واستتناجات يمكننا

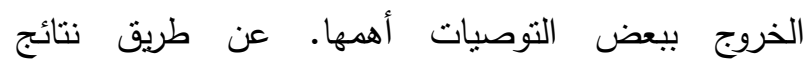

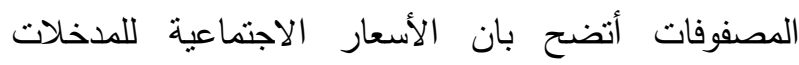

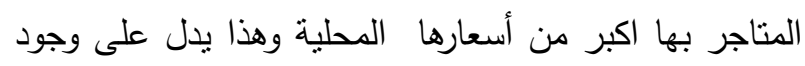

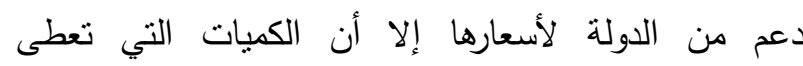

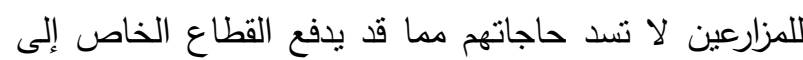

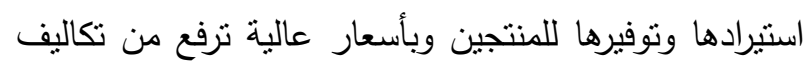

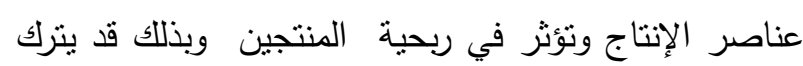
العمل الزراعي. لذا نوصي الدراسة بان تقوم الدولة بنتبني

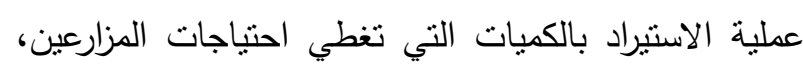

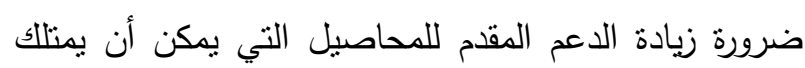
البلا أفضل ميزه نسبية فيها والمحاصيل التي تحقق اكبر ربحية اجتماعية وخاصة من اجل تحسين استغلال الموارد

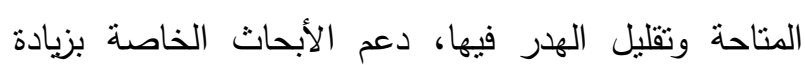
الإنتاجية وذلك بإدخال أصناف جديدة من البذور عالية

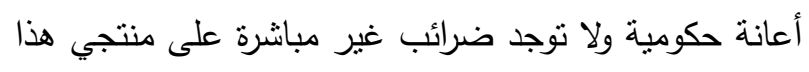

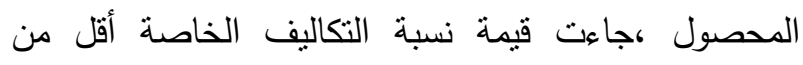
الواحد، إذ بلغت نحو 0.44 مشيرة إلى إن الاستثمار في لني

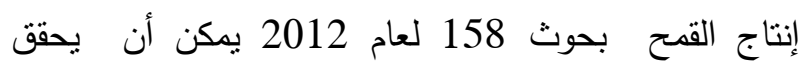

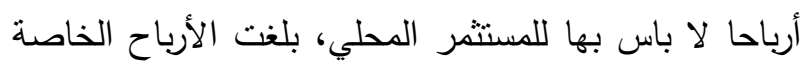

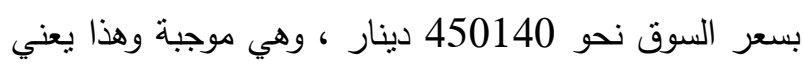
أن محصول القمح بحوث 158 رابح، هناك دعم للمدخلات

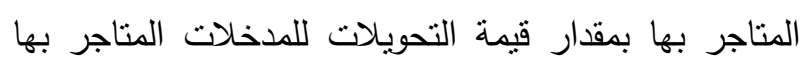
والبالغة نحو 4537 دينار /دونم.

ثانيا: عنبر البركة بحوث2

بلغ قيمة معامل الربحية نحو 2.57 مشيرة إلى إن نظام

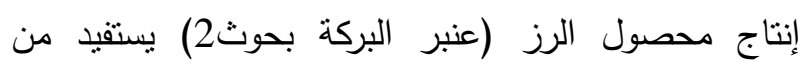

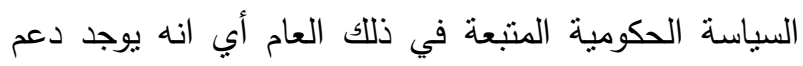
للمنتج المحلي من لدن الدولة.بلغ معامل كلفة المورد المحلي نحو 0.54 أشار إلى إنه يمكن أن يكون هناك ميزة نسبية لإنتاج محصول الرز (عنبر البركة بحوث 2) ، نؤكد قيمة لئل

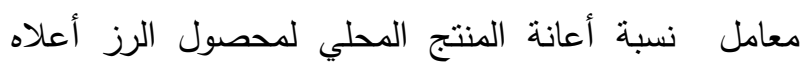

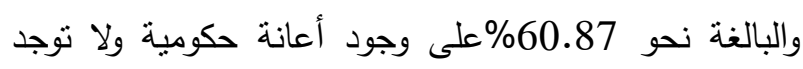
ضرائب غير مباشرة على منتجي هذا المحصول. جاءت قيمة نسبة التكاليف الخاصة أقل من الواحد إذ بلغت نحو 0.31

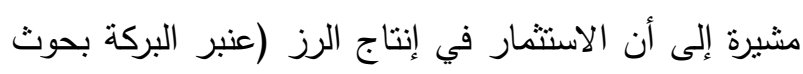

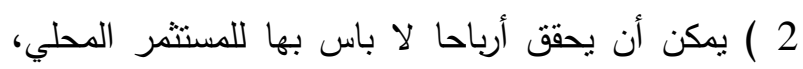
بلغت الأرباح الخاصة بسعر السوق نحو الهو 857360 دينار

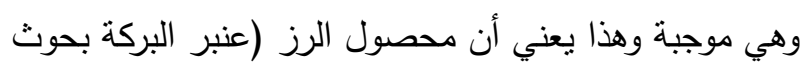

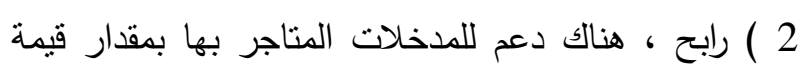
التحويلات للمدخلات المتاجر بها والبالغة نحو 1111.2 دينار /دونم.

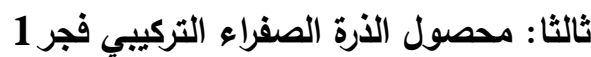
بلغ قيمة معامل الربحية نحو 1.78مشيرة إلى إن نظام إنتاج

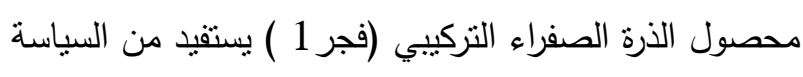
الحكومية المتبعة في ذلك ، بلغ معامل كلفة المورد المحلي نحو 0.27 أي أقل من الواحد الصحيح وجاء بقيمة موجبة أنشارت إلى إنه يمكن أن يكون هناك ميزة نسبية لإنتاج

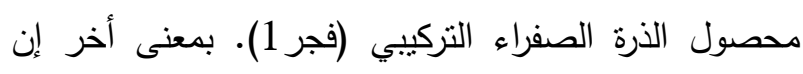

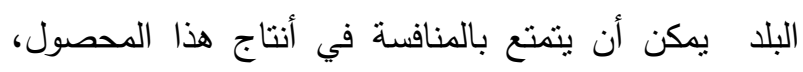

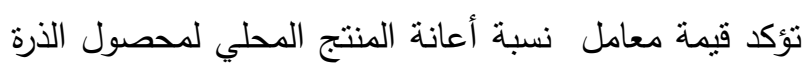


7.AL- Zubai. A. M. 2014, Agricultural Price Analysis and Policy, the first edition, IraqBaghdad, p 202-204.

8.Alex, W. N. 2008, Identify opportunities in Ghana agriculture: result from a policy analysis matrix, Indian J. of Agric. Econ. 23 (1) : 520-522.

9.Azal, I. M. 2013, The Economic Evaluation of one of the Production of Wheat Farms in the Area's Island, Province 21, Al-hafrea Township, Technical Institute, Essaouira, p 12. 10.Barbaz, D. S. 2014, Economic Evaluation for the Production of Wheat on A Farm Alabegi, The Iraqi Journal of Agricultural 45(2) ,College of Agriculture, University of Baghdad, P.170.

11.Central Statistical organization and Information Technology, Statistical of Agriculture data, The Ministry of Planning, Baghdad,2012, P 138.

12.General Company for Grain Trade, Department of Transportation statistics, pledges, Planning Department, Ministry of Commerce, Baghdad,2012, P 56.

13.General Company for the Marketing of Petroleum Products, the Oil Ministry Statistics for the Marketing of Petroleum Products for the Year (2000 -2001 -2011-2012 -2013), the Ministry of Oil, Baghdad, P67.

14.Green, R. 2009, The Costs of Indonesian sugar policy: A policy analysis matrix Approach. American J. of Agric. Econ. 72 (11): 5-442.

15.Khalaf, B. 2007, The Policy of Dumping Effect on Agricultural Production in Iraq, Research Presented to A Seminar Centre for Market Research and Consumer Protection, $\mathrm{P}$ 20.

16. Monke, E. A. and S. R. 1989, The Policy Analysis Matrix for agricultural development, Ithaca, Cornell University Press, New York, P.15.

17.Qays, T. J. 2013, The Effect of Government Intervention in Agricultural Prices on Agricultural Production - Baghdad province Case study, M.Sc. Thesis, Department of Agricultural Economics, College of Agriculture, University of Baghdad, p.34. 18.Research and Statistics Department, Central Bank, Official exchange rate and standard conversion Factor and publishing global commodity prices,2012. Baghdad, P10.

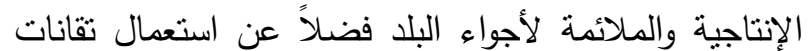

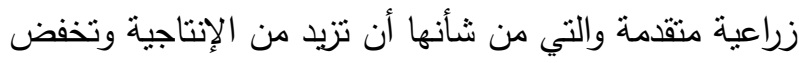

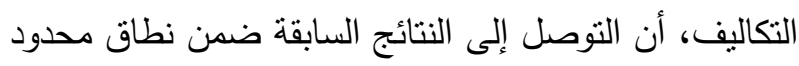

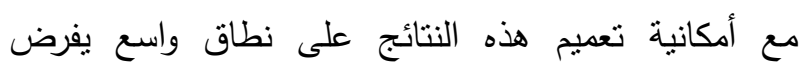
تساؤلات حول جدوى استخدام تكنيك مصفوفة تحليل السياسة

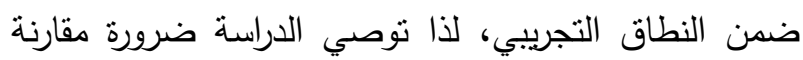
نتائج الدراسة ضمن النطاق التجريبي وعلى المحاصيل المعتمدة في الدراسة مع نتائج النطاق الواسع وللمحاصيل نفسها لكي يمكن البت نهائياً في مدى صلاحية تكنيك لندان مصفوفة تحليل السياسة ضمن النطاق المحدود ،أعطاء أولوية الاستثمار في البحث العلمي من قبل المراكز البحثية

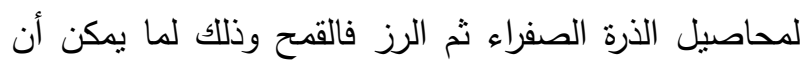
يتميز بة البلد من أنتاج حسب ذللك الترنيب. مع انه جميع المحاصيل أثثتت ميزه نسبية للبلد في أنتاجها. ألا أن هناك محددات أخرى تحد من تلك الميزة كنقص المياه وملائمة الأراضي لزراعة تلك المحاصيل والإمراض وغيرها.

\section{REFERENCES}

1.Agricultural Research Department, Agricultural Statistics, publications from wheat crops, 2012. The Ministry of Agriculture, Baghdad .P 21.

2.Al- ajlouni, M., S. S. 2010, Economic Feasibility Study and Evaluation of projects, the Arabic edition, Dar Yazouri for Publishing and Distribution, Amman Jordan, p 69.

3. Al- Dabbagh, J. 2008, The Agricultural Investment Economics, Part II, the First edition, Baghdad, Iraq, P.139.

4.Al- Hadeethi, S. T. 2006, Measuring the Economic Efficiency of the Major Vegetable Crops in Iraq, Journal of Agricultural Science, College of Agriculture, University of Baghdad, Vol. 25 (2):340.

5.Al- sadi .M .A .2010, The Feasibility of Current Public Investment in Agricultural Sector in Iraq for the Period (1980 - 2005), MSc. Thesis, Department of Agricultural Economics, College of Agriculture, University of Baghdad, p 90.

6.Al- saidi .A. J. 2011, Agricultural Policy Analysis Of Rice System In Iraq For The Year 2007 By Using Analysis Matrix , Ph. D. Dissertation , Department of Agricultural Economics, College of Agriculture, University of Baghdad, p87. 
19.State Company for the Agricultural Supplies, Fertilizer Prices, 2012. The pricing Department, Unpublished Data, the Ministry of Agriculture, Baghdad, P42.

20.Wigdan, K. J. 2011, Planning For Production of the four Main Crops (Wheat,
Barley, Rice \& Maize) In Iraq By Using Policy Analysis Matrix, Ph. D. Dissertation, Department of Agricultural Economics, College of Agriculture, University of Baghdad, p.87. 